\title{
On the participation of wind energy in response and reserve markets in Great Britain and Spain
}

\author{
Calum Edmunds ${ }^{1, *}$, Sergio Martín-Martínez ${ }^{2}$, Jethro Browell ${ }^{1,}$, Emilio \\ Gómez-Lázaro ${ }^{2,}$, Stuart Galloway ${ }^{1,}$
}

\begin{abstract}
Power systems require a wide range of ancillary services in order to function and renewables will be expected to provide such services in line with their increasing penetration. This paper focuses on the participation of wind energy in response and reserve markets. We compare the present situation in Great Britain (GB) and Spain, and make recommendations to support future development. Wind is already participating in a limited range of ancillary services in both countries: frequency response in GB and reserve services in Spain. We analyse the effects of market design, subsidy arrangements, and systemspecific needs on participation of wind in these markets, and then make policy recommendations designed to enable increased participation from wind. Our recommendations include the use of short-term markets to enable the use of accurate wind power forecasts, capacity-based subsidy schemes to avoid distorting ancillary service markets, and facilitating the participation of aggregated (single and mixed technology) resources. Country-specific recommendations include revising the current settlement process in GB to remove the incentive to over-estimate short-term generation forecasts, and establishing a competitive frequency containment reserve market in Spain. These recommendations are supported by analysis of publicly available market data.
\end{abstract}

\footnotetext{
* Corresponding author

Email address: calum.edmunds@strath.ac.uk (Calum Edmunds) UK.

${ }^{1}$ Department of Electronic and Electrical Engineering, University of Strathclyde, Glasgow,

${ }^{2}$ Renewable Energy Research Institute and DIEEAC-ETSII-Ab. Universidad de CastillaLa Mancha, 02071 Albacete, Spain
}

Preprint submitted to Renewable and Sustainable Energy Reviews

August 29, 2019 
Word count: 9939

Keywords: Balancing Markets, Wind Energy, Reserve Markets, Frequency

Response, Curtailment [

\section{Introduction}

The large-scale integration of wind power generation is fundamentally changing the way power systems and electricity markets operate as the wind resource is variable with limited predictability and has zero fuel cost. Energy policy is evolving to meet the requirements for ancillary services (AS) necessary to ensure the economic and reliable delivery of power with a high penetration of renewables [1, 2, 3]. To date, this has largely meant increasing the provision of reserve and balancing services from coal and gas power plants. However, as these are phased out, wind, solar and emerging technologies such as battery energy storage and demand side response will be required to play an increasing role in AS provision. Improved forecasting coupled with markets running closer to real time will be key enablers for increased participation of wind in these markets.

An in depth study comparing balancing costs in GB and Germany was carried out in [4]. Recommendations are made for increasing the participation of variable renewable energy sources in reserve markets, including; shortening balancing product lengths, holding reserve auctions in GB closer to delivery, and implementing a GB balancing mechanism (BM) style replacement reserve (RR)

\footnotetext{
Acronyms: aFRR, Automatic Frequency Restoration Reserve; AS, Ancillary Service; BM, Balancing Mechanism; BMU, Balancing Mechanism Unit; CCGT, Close Cycle Gas Turbine; CECRE, Renewable Energy Control Centre; CfD, Contract for Difference; CHP, Combined Heat and Power; DA, Day Ahead; DAM, Day Ahead Market; DSF, Demand Side Flexibility; EFR, Enhanced Frequency Response; ENTSO-E, European Network of Transmission System Operators; FCR, Frequency Containment Reserve; FFR, Firm Frequency Response FR, Fast Reserve; FiT, Feed in Tariff; FPN, Final Physical Notification; FRR, Frequency Restoration Reserve; GB, Great Britain; HVDC, High Voltage Direct Current; ID, Intraday; MFR, Mandatory Frequency Response; mFRR, Manual Frequency Restoration Reserve; OCGT, Open Cycle Gas Turbine; OMIE, Operador do Mercado Ibérico de Energia, BRP, Balance Responsible Party; ROC, Renewable Obligation Certificate; RR, Replacement Reserve; STOR, Short Term Operating Reserve; TCR, Technical Constraint Resolution; TCRM, Technical Constraint Resolution Market; TSO, Transmission System Operator; WE,Wind Energy; XBID, Cross Border Intraday Market
} 
market in Germany. The effect of increasing penetration of wind generation on frequency containment reserve (FCR) requirements in GB has been explored using a model of the GB transmission system in [5]. It was found that a significant increase in FCR will be required at low load levels and high wind production unless wind turbines contribute to system inertia. The primary reason for low participation of wind in FCR markets is a combination of prohibitive market arrangements (gate closure beyond limits of predictability) and unattractive economics as today FCR has a low value compared to energy, especially where energy receives additional subsidy payments. However, as the penetration of zero-marginal cost generators increases, and subsidy schemes expire, the relative value of ancillary services is expected to increase significantly [2]. A GB government advisory body has recommended that new markets should be developed for ancillary services to allow new technologies - including wind - to participate more easily [6].

In Spain, wind energy has been subject to a new regulatory framework since 2014 [7]. In 2014, subsidies for renewable energy changed from Feed-in Tariffs to a capacity-based investment bonus to fix profitability at $7.5 \%$ throughout the regulated lifetime of the project $[8]$. Over $4 \mathrm{GW}$ of new wind energy capacity is expected to be installed by 2020 following two recent auctions for investment bonuses [9]. This change has incentivised wind energy to participate more actively in day-ahead (DA), intraday (ID) and balancing markets [10]. For example, wind energy is making a considerable contribution to volumes traded in the new European cross border ID market (XBID) which opened in June 2018. In 2018, 1597 GWh was traded on XBID representing $4.5 \%$ of the total ID market volume [11. Wind energy has been able to provide bids in FRR, RR and Imbalance Management markets in the Spanish power system since 2016 [10].

In [12] it is shown that the business case for wind is strengthened with increased participation in DA and frequency regulation markets. It is also highlighted that appropriate support regimes can improve the contribution of wind to system flexibility. A good example of this is in Denmark, where the number of full-load hours for which premium feed-in tariff is given to wind generators is 
limited. This has increased participation of wind in DA markets and incentivised wind to curtail during times of negative prices (a symptom of oversupply), postponing subsidy support to times of positive prices [12].

WindEurope, the association promoting wind power in Europe and worldwide, has proposed "10 commandments" to aid the participation of wind in balancing markets [13]. The 10 commandments propose market designs conducive to increasing value and participation from wind generators. They recommend that balancing products should be harmonised and shortened; lessons can be learned from Italy, France and Belgium where timeframes for frequency restoration reserve (FRR) are as short as 15 minutes. They also recommended marginal pricing of balancing products and that the lead time for procurement of balancing products should be shortened.

Numerous research and demonstration projects have explored the potential for wind energy to provide a wide range of balancing services. These include the pilot tests performed at the Estinnes wind farm (Belgium) for automatic frequency restoration reserve (aFRR) [14], a $21 \mathrm{MW}$ wind power plant test providing mFRR in the downward direction for 1 hour described in [15]; the TWENTIES project, where the Spanish Transmission System Operator (TSO), in cooperation with Iberdrola, tested the participation of wind farms in aFRR [16]; several projects in Germany which have developed control methods for wind energy [17, wind energy and photovoltaics [18, and the aggregation of renewable plants [19] to participate in balancing markets; and the WINDGRID project ('Wind on the grid'), which trialled control techniques for a wind farm cluster in Portugal [20]. In GB, tests demonstrating wind farms providing FCR include those at Burbo Bank offshore wind farm 21 and trials of coordinated FCR in the Enhanced Frequency Control Capability project [22]. In [23], authors present the cost savings and technical effects of wind balancing provision for a 2025 scenario in Germany.

While many wind farms today are technically able to provide a wide range of ancillary services, improving this capability, particularly frequency response, is an active research area. This includes wind farm control strategies to: optimise 
power output from multiple generators [24, provide temporary overproduction [25], minimise wake effects to increase available power reserve [26] and coordination with conventional generators [27, 28, 29]. While increasing the technical capability of wind to provide reserve is important for increasing participation in present and future markets, most large wind farms already have the capability to provide reserve in GB and Spain. The main reason for a low penetration of wind in reserve markets is economic, not technical, and is a consequence of both market design and price signals, including subsidy arrangements.

The effect of subsidies in distorting wholesale electricity markets, at times producing negative prices, is well understood and has been observed in GB [30], the US [31] and Germany [32, among others. The effect of subsidies on the participation of renewables in reserve markets, touched on in [4], is an area that requires further study. This paper covers this topic in greater detail in relation to the GB and Spanish power systems, with current subsidy regimes and for subsidy free generation, which will become the norm in decades to come.

This paper makes a series of market design and policy recommendations to enable greater participation of wind generators in frequency response and reserve markets. It also contributes a novel a comparison of recent developments with respect to provision of reserve from wind in GB and Spain, plus supporting analysis of relevant market data. We provide insights into the effects of subsidies on the participation of wind in reserve markets, the impact of specific elements of energy market design on incentives to participate in ancillary service markets, and the impact of response and reserve product specifications on the ability of wind generators to offer those services. Key policy recommendations are detailed in Section 7 and include the following:

- Implementing capacity-based subsidy mechanisms instead of energy based subsidies. Capacity based subsidies do not impede wind's participation in reserve and response markets whereas energy based subsidies do.

- In GB, the current policy of curtailment payments based on operatorsubmitted notifications of expected generation should be revised to incen- 
tivise accuracy rather than over-estimation.

- In Spain, it is recommended to establish a competitive FCR market that facilitates participation from renewable energy sources.

For consistency, the ENTSO-E definitions of reserve 33 are used; these are summarised along with equivalent GB and Spanish reserve products in Table 1 The remainder of the paper is structured as follows with policy recommendations made at the end of each section and summarised in Section 7, Section 2 describes and compares the Spanish and GB context, Section 3 concerns energy balancing, RR and wind curtailment, FRR and FCR markets are considered Sections 4 and 5 respectively. Future trends are discussed in Section 6 and, finally, Section 7 provides conclusions and policy recommendations linked to the findings of this work. 
Table 1: Reserve definitions, timescales and product descriptions

\begin{tabular}{|c|c|c|c|c|c|}
\hline \multicolumn{2}{|c|}{ ENTSO-E Network code 33} & \multicolumn{2}{|r|}{ GB } & \multicolumn{2}{|r|}{ Spain } \\
\hline Timeframe & Terminology & Timeframe & Description & Timeframe & Description \\
\hline$<30$ s & $\begin{array}{l}\text { Frequency } \\
\text { Contain- } \\
\text { ment Reserve } \\
\text { (FCR) }\end{array}$ & $<30$ s & $\begin{array}{l}\text { Mandatory and Firm Frequency Response } \\
\text { (MFR and FFR). MFR accessed by TSO } \\
\text { intraday, FFR tendered month ahead. } \\
\text { Includes Primary (10s) and Secondary (30s) } \\
\text { under-frequency response, and High (10s) } \\
\text { over frequency response. May be dynamic } \\
\text { (droop characteristic) or static (activated at } \\
\text { frequency threshold). Enhanced Frequency } \\
\text { Response (EFR, 1s) is a new, fast dynamic } \\
\text { service. }\end{array}$ & $<30$ s & $\begin{array}{l}\text { Frequency Containment Reserve (FCR), no } \\
\text { commercial market, generators must provide } \\
\text { (or contract from a third party) FCR } \\
\text { equivalent to } 1.5 \% \text { of production. }\end{array}$ \\
\hline $\begin{array}{l}30 \mathrm{~s} \text { to } 15 \\
\min \end{array}$ & $\begin{array}{l}\text { Frequency } \\
\text { Restora- } \\
\text { tion Reserve } \\
\text { (FRR) }\end{array}$ & $<2 \min$ & $\begin{array}{l}\text { Fast Reserve }(<2 \mathrm{~min}) \text {, tendered monthly and } \\
\text { balancing actions taken by the TSO in the } \\
\text { BM ( }>2 \mathrm{~min}) \text {. Secondary MFR and FFR are } \\
\text { sustained for at least } 30 \text { minutes. }\end{array}$ & $\begin{array}{l}30 \mathrm{~s} \text { to } 15 \\
\min \end{array}$ & $\begin{array}{l}\text { Secondary reserve or 'automatic frequency } \\
\text { restoration reserve' (aFRR) procured via a } \\
\text { pay-as-clear day-ahead market for availability } \\
\text { and utilisation energy. }\end{array}$ \\
\hline$>15 \min$ & $\begin{array}{l}\text { Replacement } \\
\text { Reserve (RR) }\end{array}$ & $\begin{array}{l}20 \text { min to } \\
4 \text { hour }\end{array}$ & $\begin{array}{l}\text { Short-term operating reserve (STOR, } 20 \text { min) } \\
\text { tendered for every } 3 \text { months. The BM }(2-90 \\
\text { min) and an ID power exchange ( }>90 \mathrm{~min}) \\
\text { are used by the TSO to access RR. }\end{array}$ & $\begin{array}{l}15 \text { min to } \\
2 \text { hour }\end{array}$ & $\begin{array}{l}\text { Tertiary reserves }(\mathrm{RR}) / \text { Day-ahead market } \\
\text { (Marginal price) }\end{array}$ \\
\hline
\end{tabular}




\section{Overview of GB and Spanish Power Systems}

The Spanish and GB electricity systems have a similar penetration of wind power (see Tables 2 and 3 respectively) and share similar difficulties with congestion and limited interconnection with other countries. They are both part of the European Multi-Regional Coupling arrangements, which couple day-ahead power auctions subject to cross-border transmission capacity between participating countries, but have quite different ID and ancillary service market arrangements.

\subsection{Electricity markets: Spain}

The wholesale electricity market in Spain is organised as a sequence of DA and ID pool markets, with long-term trading via bilateral contracts 38. Approximately $65 \%$ of traded volume was in pool markets and the remainder in bilateral contracts in 2017. A schematic timeline of these markets, balancing markets and technical constraint resolution markets (TCRM) in DA, ID and in real time is shown in Figure 1 .

Currently, Spain has an installed wind capacity of $22.9 \mathrm{GW}$ with more than 1000 wind farms widely spread geographically (see Figure 2). Most Spanish wind farms have a name-plate capacity of $50 \mathrm{MW}$ or below, as historically this was a requirement to receive Feed In Tariffs (FiTs). Spain's wind farms are grouped in to 232 schedulable units with nominal power capacities between 0.2 and $5472 \mathrm{MW}$ and are managed by 33 market agents [39].

The Spanish DA and average subsidy prices paid to wind energy producers from 2015 to 2018 are shown in Table 4 . The prices in the day-ahead market (DAM) have risen from an average price of $40 € / \mathrm{MWh}$ in 2016 to $57 € / \mathrm{MWh}$ in 2018, illustrated in Figure 3 One of the contributing factors to this increase is higher bids provided by wind energy agents since the end of the FiT [0].

\subsection{Electricity markets: $G B$}

The wholesale electricity market in GB is dominated by over-the-counter trades up to two years ahead of delivery, representing $83 \%$ of traded volumes in 
Table 2: Spain generation mix $2018^{1}$

\begin{tabular}{l|l|l|l|l|l} 
Technology & \multicolumn{3}{|c}{ Capacity } & \multicolumn{2}{c}{$\begin{array}{l}\text { Generation } \\
\text { Factor }\end{array}$} \\
& [GW] & {$[\%]$} & {$[$ TWh] } & {$[\%]$} & [\%] \\
\hline \hline Gas & 24.5 & 23.5 & 26.4 & 10.4 & 12 \\
Wind & 23.0 & 22.1 & 48.9 & 19.3 & 24 \\
Hydro & 17.0 & 16.3 & 34.0 & 13.4 & 23 \\
Coal & 9.5 & 9.1 & 34.8 & 13.7 & 42 \\
Nuclear & 7.1 & 6.8 & 53.1 & 20.9 & 85 \\
Interconnectors & 5.8 & 5.6 & 11.1 & 4.4 & 22 \\
CHP & 5.7 & 5.5 & 28.9 & 11.4 & 58 \\
PV Solar & 4.4 & 4.2 & 7.3 & 2.9 & 19 \\
Pumped hydro & 3.2 & 3.4 & -1.2 & -0.5 & 4 \\
Thermal Solar & 2.3 & 2.2 & 4.4 & 1.7 & 22 \\
Other & 1.7 & 1.6 & 5.8 & 2.3 & 39 \\
\hline Total & 104.3 & & 253.5 & &
\end{tabular}

${ }^{1}$ Data for capacity and generation is from 34 .

2 Generation / (Capacity * 8760) * $100 \%$

${ }^{3}$ Pumped Hydro generation is the net of pumping demand of $3.2 \mathrm{TWh}$ and generation of $2.0 \mathrm{TWh}$.

${ }^{4}$ Biomass and Waste. 
Table 3: GB generation mix $2018^{1}$

\begin{tabular}{l|l|l|l|l|l} 
Technology & \multicolumn{3}{|c}{ Capacity } & Generation & $\begin{array}{l}\text { Capacity } \\
\text { Factor }\end{array}$ \\
& GW & \% & TWh & $\%$ & [\%] \\
\hline \hline Gas & 30.4 & 30.2 & 115.3 & 34.7 & 43 \\
Wind & 20.7 & 20.6 & 51.7 & 15.6 & 29 \\
Solar & 13.0 & 12.9 & 11.6 & 3.5 & 10 \\
Coal & 11.7 & 11.6 & 15.4 & 4.6 & 15 \\
Nuclear & 9.2 & 9.2 & 60.6 & 18.3 & 75 \\
Biomass & 4.1 & 4.1 & 16.1 & 4.9 & 45 \\
Interconnectors & 4.0 & 4.0 & 21.9 & 6.6 & 63 \\
Pumped Hydro & 2.8 & 2.8 & -0.2 & -0.1 & 1 \\
Hydro & 1.5 & 1.5 & 3.2 & 1.0 & 24 \\
Other & 3.1 & 3.1 & 0.8 & 0.2 & 3 \\
\hline Total & 100.5 & & 296.4 & &
\end{tabular}

${ }^{1}$ Data for capacity is from [35] and for generation is from [36] and 37]

${ }^{2}$ Pumped Hydro generation is the net of pumping demand of 2.9 TWh and generation of 2.7 TWh. Pumped hydro generation only capacity factor is $12 \%$.

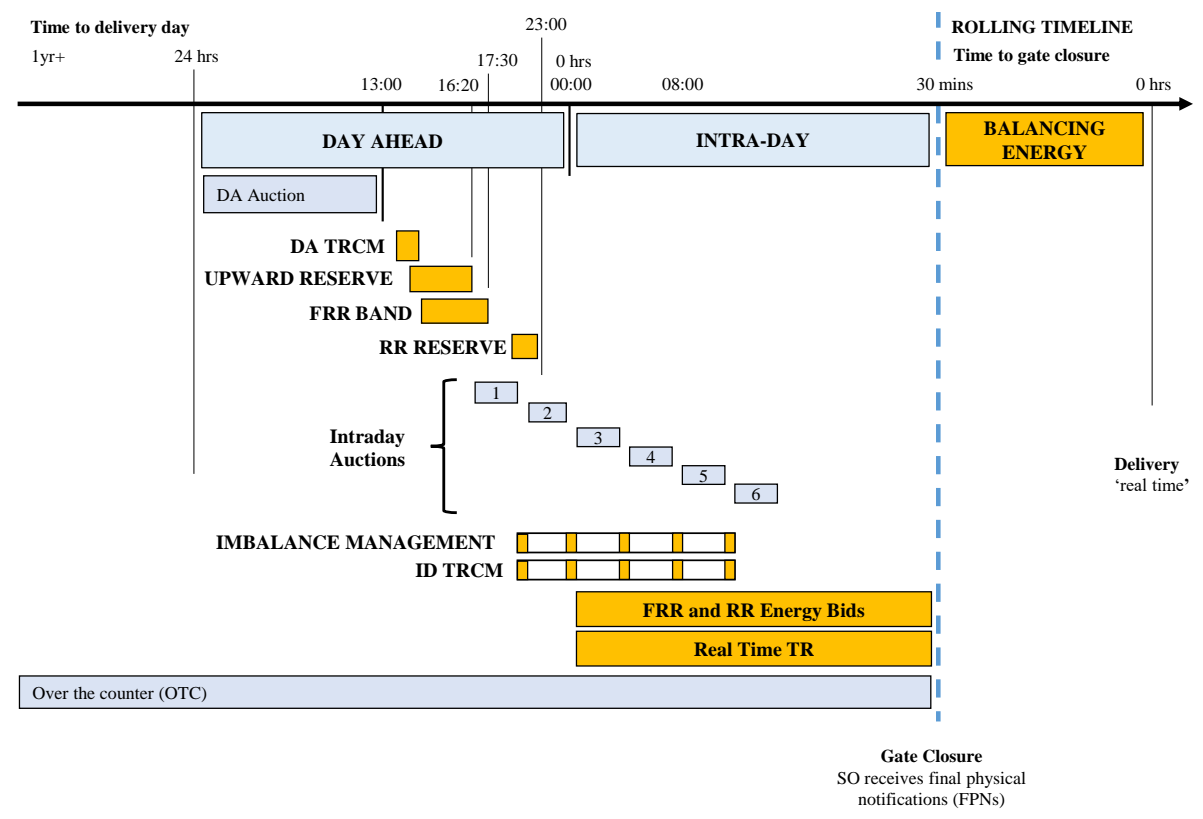

Figure 1: Timeline for Spanish electricity markets markets; data: 11. 


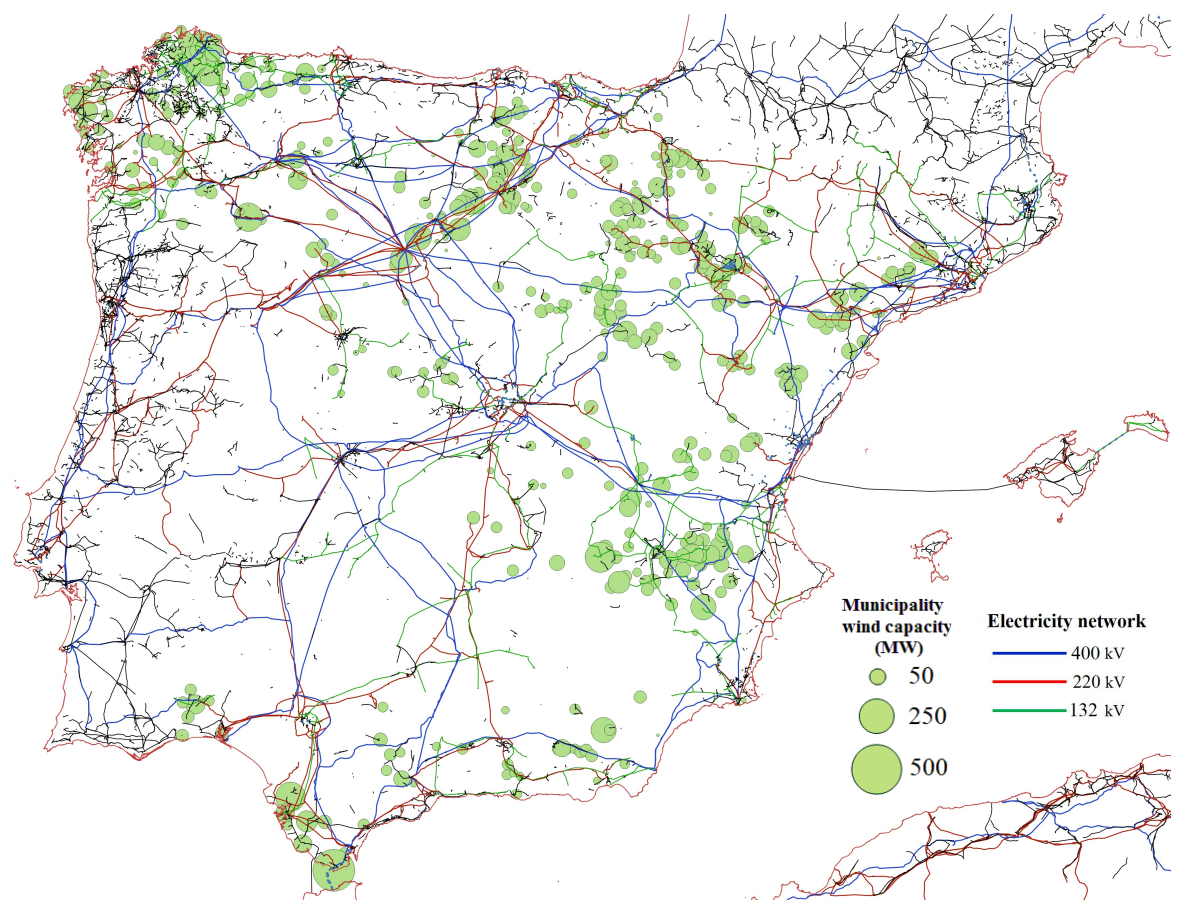

Figure 2: Spanish power system transmission network and distributing of installed wind energy capacity (aggregated by province) in 2018. Wind capacity in Portugal is not displayed; data: [11.

Table 4: Spain Electricity Prices - DA and Incentives ${ }^{1}$

\begin{tabular}{l|l|l|l|l|} 
& \multicolumn{5}{|c}{ Volume Average Price (€/MWh) } \\
Market & 2015 & 2016 & 2017 & 2018 \\
\hline DA Market & 51.7 & 40.6 & 53.4 & 57.3 \\
Incentives & 26.1 & 26.3 & 30.9 & 30.1
\end{tabular}

${ }^{1}$ Incentives are paid by capacity. The effective price has been calculated as total incentives paid divided by total energy generated by incentivised wind farms. 


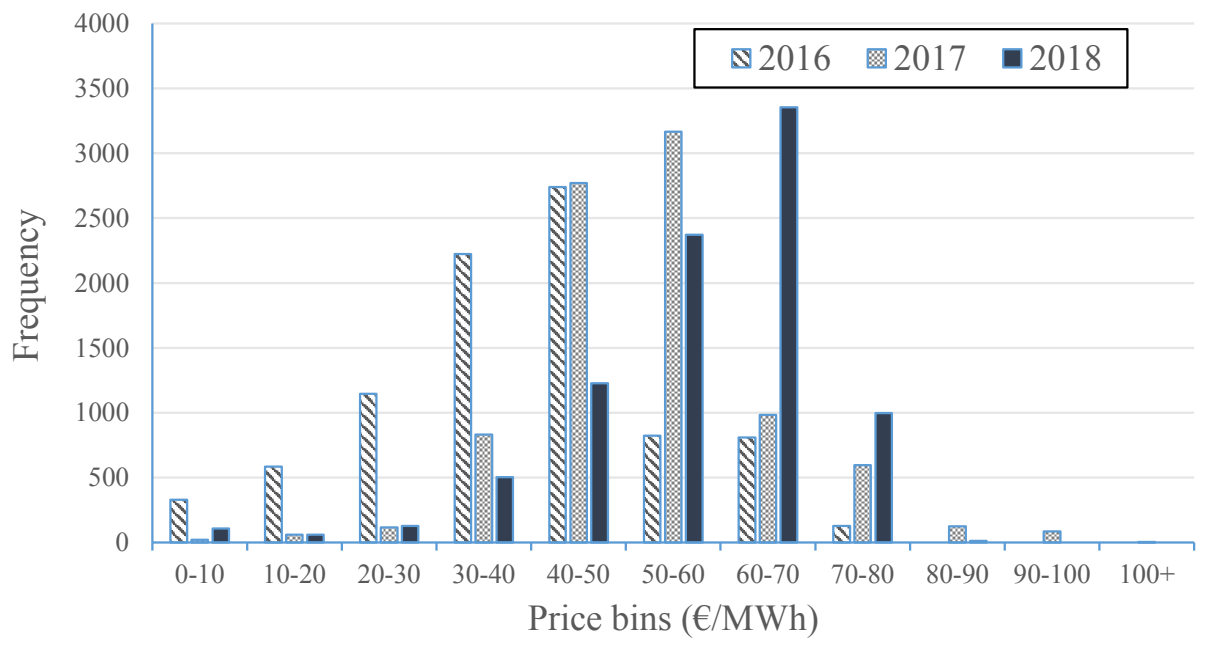

Figure 3: Spain Operador do Mercado Ibérico de Energia (OMIE) Auction Price Histogram 2016-2018; data: 41 .

2017 [42]. Closer to delivery, energy is traded via a day-ahead auction for hourly products and four further auctions (two of which only opened on 30 September 2018) and an intra-day exchange for half-hourly products (see Figure 5D.

Larg $\AA^{3}$ wind farms must be registered as 'BM units' (BMUs), and as such participate in at least the BM and mandatory ancillary services, in addition to the wholesale electricity market. There are 122 large wind farm BMUs, 75 of which are onshore in Scotland and 39 of which are off the coast of England (see Figure 4 for geographical distribution). Approximately $40 \%$ of wind farm capacity is not large and is connected at distribution level, the majority of this embedded generation has limited ability to participate in markets other than wholesale energy at present. Embedded wind farms may already be BMUs by choice or as a condition of their connection agreement, or from December 2019 as a 'secondary BMU' forming part of an aggregator's portfolio in a given region

\footnotetext{
${ }^{3}$ 100MW England \& Wales, 50 MW South Scotland (Scottish Power Transmission region), 10 MW North Scotland (Scottish Hydro-Electric Transmission region) and transmission connected regardless of capacity.
} 


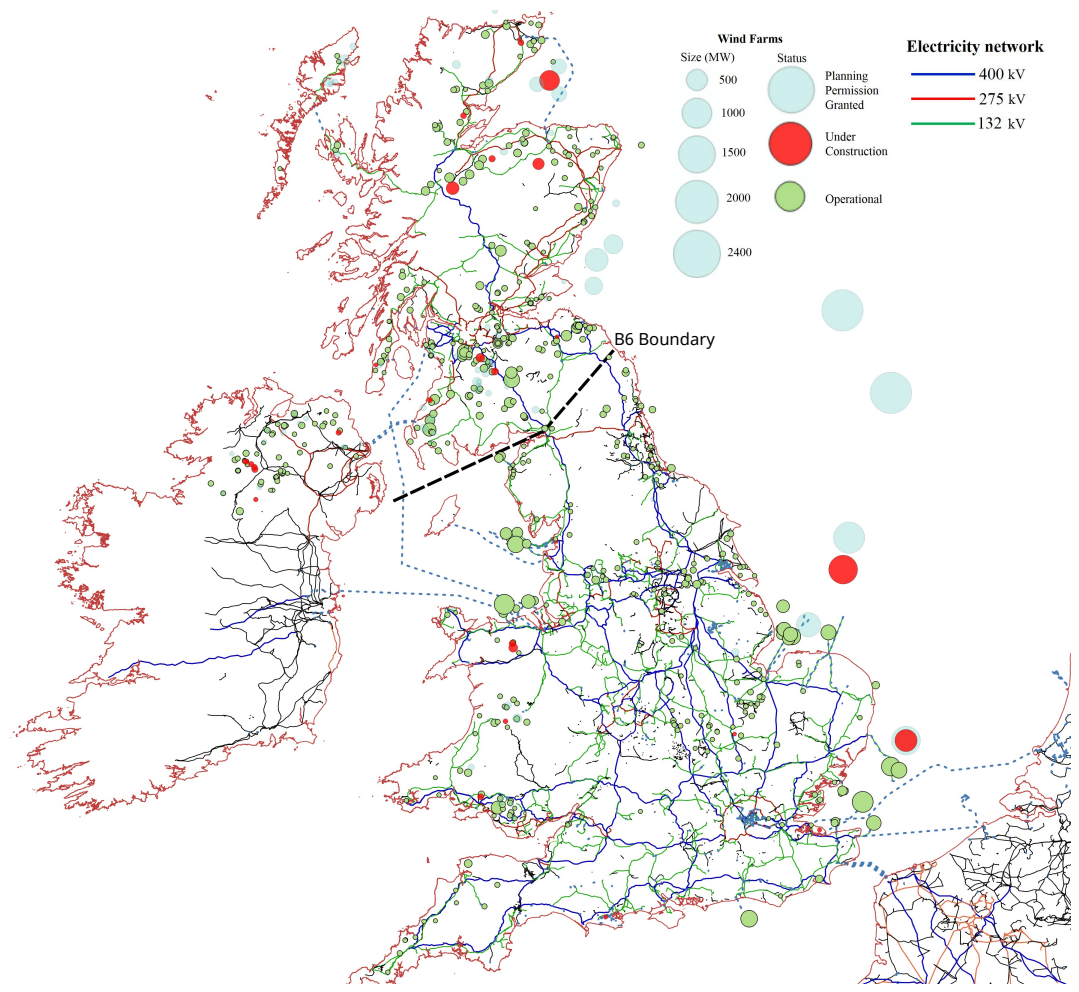

Figure 4: GB transmission system and wind energy distribution 2018; data: 44, 45, 46. $132 \mathrm{kV}$ regarded as transmission system in Scotland but not in England and Wales. The 'B6' boundary is highlighted as flows across this part of the network are often constrained.

43.

The average DA electricity prices in GB have risen by over $30 \%$ from 2016 to 2018 (see Table 5) and instances of prices over $£ 60 /$ MWh have increased significantly, particularly in 2018 (see Figure 6). This has been influenced by rising gas prices and the EU Emission Trading Scheme carbon price, (imposed on fossil fuel generators), which has more than doubled over the course of 2018.

\subsection{Wind Subsidies: Spain}

From 1998 to 2012 FiTs have supported the growth of wind capacity in Spain, with changes to FiT regulations taking effect in 2004 and 2007. This stimulated significant growth in installed capacity over the first 10 years from $1.5 \mathrm{GW}$ to 


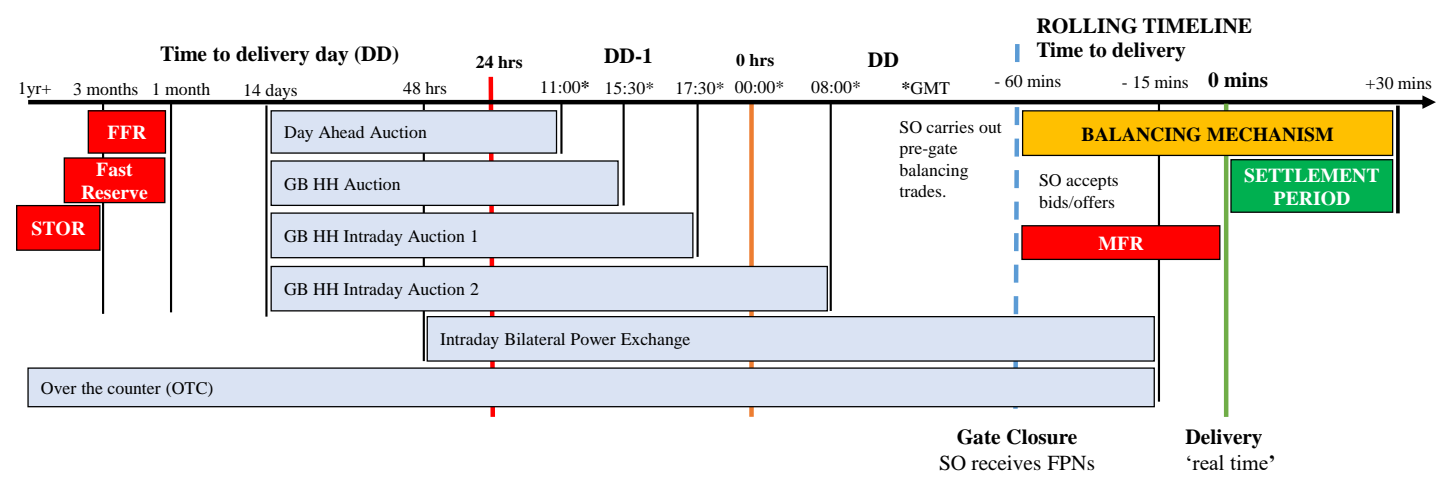

Figure 5: Timeline for GB electricity markets; data: 47 48 49. Two market operators run day-ahead markets in GB, EEX (EPEX SPOT) and Nordpool (N2EX), which are coupled via a virtual interconnector in order to clear at the same price. Only one is illustrated above for simplicity. The two ID auctions were only established in late 2018.

Table 5: GB Electricity Prices - DA, Imbalance Price and ROC price; data: 42, 50, 51, 36.

\begin{tabular}{l|l|l|l|l|} 
& \multicolumn{4}{|c}{ Average Price (£/MWh) } \\
Market & 2015 & 2016 & 2017 & 2018 \\
\hline DA Baseload & 40.7 & 42.6 & 46.3 & $53.4^{3}$ \\
N2EX DA & 41.2 & 41.5 & 46.1 & 58.1 \\
Imbalance Price & 36.7 & 39.4 & 44.3 & 57.3 \\
ROC Buy-out & 44.3 & 44.8 & 45.6 & 47.2
\end{tabular}

${ }^{1}$ In the Market Coupling Arrangements, APX and N2EX are coupled by a virtual interconnector of infinite capacity and zero losses.

${ }^{2}$ Volume weighted.

${ }^{3}$ Up to end of October 2018 


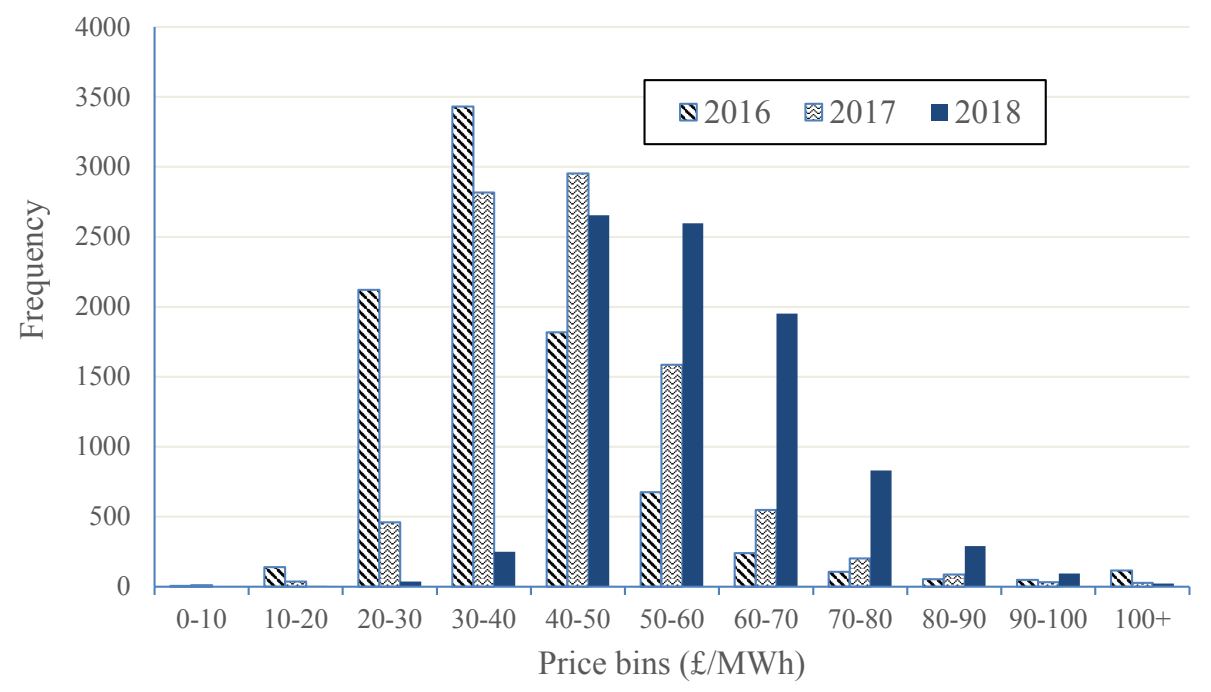

Figure 6: GB N2EX Auction Price Histogram 2016-2018; data: 50].

16.7 GW, eventually reaching $22 \mathrm{GW}$ in 2012. Under the Spanish FiT regime, wind farm operators could choose between two options: a guaranteed feed-in tariff or a bonus paid on top of the electricity price achieved on the day-ahead market. The last FiT and bonus values in 2012 were $73 € / \mathrm{MWh}$ and $29 € / \mathrm{MWh}$ respectively [40].

In 2012 there was a moratorium on the installation of new renewable power plants after a repeal of FiTs for new facilities. Since 2014 the incentives were modified to be mainly for installed capacity rather than energy production, illustrated in Figure 7

These incentives are variable according to the age of the plant and the operation equivalent hours in order to obtain a reasonable cost effectiveness of 7.5 $\%$ [52. This reform left $6.3 \mathrm{GW}$ wind energy capacity commissioned prior to 2004, more than 300 wind farms, without any type of incentive and they have had to operate with only electricity market revenues since 2017. The average investment incentive from 2015 to 2018 (shown in Table 4) is significantly lower than the repealed FiTs.

Prior to April 2014 it was common for the day-ahead market to clear at 


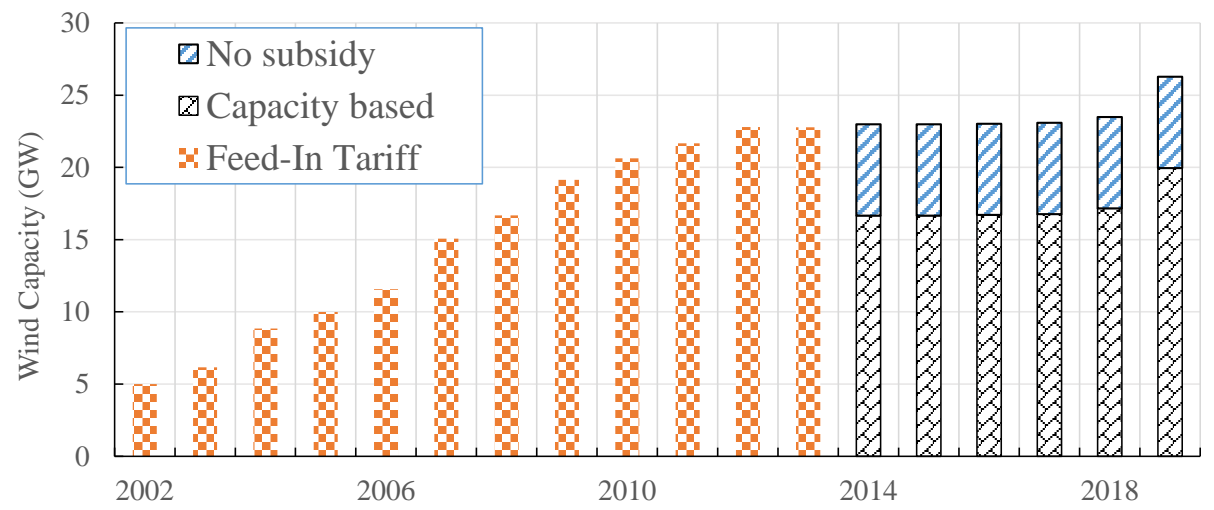

Figure 7: Spanish Wind capacity with Feed-In (energy based) subsidy, capacity based subsidy and without any subsidy; data: Figures for 2019 are forecasted.

$0 € /$ MWh in hours of low demand and high wind production. A regulatory change in April 2014, made it possible for wind farms to participate in balancing markets, eliminated the obligation of renewable energy to bid at $0 € / \mathrm{MWh}$, and has removed the priority dispatch of wind in the day-ahead market [53]. Since April 2014, the minimum day-ahead market price has been $2.3 € / M W h$, due to higher wind energy bids [41.

\subsection{Wind Subsidies: $G B$}

The majority of wind capacity in GB today is subsidised via the Renewable Obligation which issues certificates (ROCs) in proportion to energy generated [54. ROCs are issued for 15 years from first generation, regardless of the lifetime of the wind farm ROCs are issued to generators and then sold to electricity retailers who must obtain a set number of certificates each year. The ROC buy out prices have been steadily increasing year on year (see Table 5). In 2014 Contracts for Difference (CfD) auctions were introduced [55], largely for offshore wind, and are designed to apply negative pressure on subsidy prices. The ROC mechanism was closed to new entrants in April 2017 meaning CfDs are now the only subsidy mechanism available for new large scale generation,

${ }^{4}$ Except wind farms built before 2007 which had ROC contracts extended up to 2027 


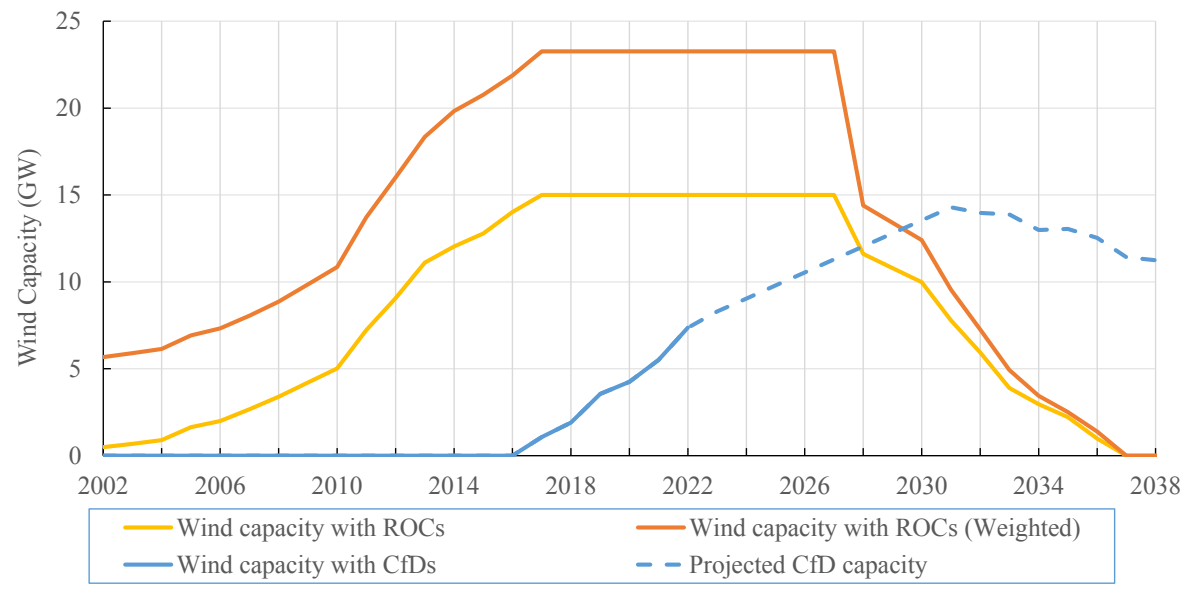

Figure 8: GB Wind capacity with ROC and CfD subsidies; data: [54, 55. The weighted capacity of ROCs is higher due to early off-shore wind farms being awarded between 1.5 and 2 ROCs/MW depending on the year of construction.

however, participation of wind in the GB capacity market is being considered for the future.

The capacity of wind with CfDs is expected to rise by 1-2 GW every 2 years beyond 2022 [56] but will not reach the peak of ROC-subsidised capacity (see Figure 8). A large capacity of wind farms with extended ROC contracts will expire in 2027 which could have a significant impact on profitability of these generators and incentivise their participation in reserve and response markets.

\subsection{System issues: Spain}

One of the main issues in the Spanish power system is the lack of large scale interconnection with mainland Europe [57]. The interconnection ratio, the ratio of interconnection capacity to installed generation capacity, for Spain is currently less than $5 \%$, well below the EU's recommendation of over $10 \%$ by 2020 and $15 \%$ by 2030 58. Keeping in mind that the actual support for the Iberian Peninsula can only come from Central Europe over the border with France, the interconnection ratio is $2.8 \%$ from the new interconnector between Spain and France via the eastern Pyrenees. Therefore, Spain is close to being 
an electrical island in terms of the ability to import or export energy. This limited international interconnection is compounded by the lack of flexibility of hydraulic production during periods of drought [59].

Development of new interconnections is continuing with projects such as the underwater interconnector under the Vizcaya Gulf, the northern interconnector between Galicia and the Minho region in Portugal, a phase-shifting transformer in Arkale and the Ceuta interconnection to the north of Africa.

\subsection{System issues: $G B$}

With the closure of large synchronous plant (particularly coal power stations, of which 7.2 GW have been closed in GB between 2013 and 2017 [60]) there are concerns around loss of inertia and rate of change of frequency (RoCoF) [35, 61]. This is more of an issue in GB than the larger synchronous area of continental Europe. GB has 4 HVDC interconnectors with a total capacity of $4 \mathrm{GW}$ with a further $18.1 \mathrm{GW}$ of interconnector capacity contracted but not operational, to connect GB with Belgium, Norway, France, Denmark, Germany and Ireland [35. GB is predominantly an importer with $84 \%$ of interconnector flows by volume being imports in 2017. The interconnectors provide a valuable source of flexibility with the French interconnector commonly varying from close to full $2.2 \mathrm{GW}$ import to $2.2 \mathrm{GW}$ export within the space of a day.

There are currently constraints at transmission level particularly at the B6 boundary between Scotland and England, highlighted in Figure 4 The Western Link sub-sea HVDC connection has increased the capacity across the B6 boundary by $2.2 \mathrm{GW}$ taking the total Scotland-England transfer capacity to $5.7 \mathrm{GW}$ 62]. Scottish wind capacity already exceeds $8 \mathrm{GW}$ and is expected to

keep growing, therefore it is likely that significant curtailment will continue to be seen in the Scottish wind fleet.

\subsection{High-level Comparison}

Although bilateral trades make up a larger share of total traded volumes in GB compared to Spain (partly due to higher churn i.e. the same unit of energy 
being traded multiple times), a significant percentage of delivered volume in GB is traded in the DA auctions at over $40 \%$. In GB and Spain, significant volumes of adjustments are being made close (up to 1 hour) to delivery which reduces the reliance on balancing actions and provides better foresight to the TSO. However, moving gate closure closer than 1 hour may increase power system operational costs 63].

In GB, wind farm subsidies are based on energy output, whereas in Spain, energy based subsidies have been replaced with capacity based subsidies or no subsidy at all (for 6.3 GW of wind capacity). There is a marked difference between energy-based subsidy mechanisms, such as those in GB, and capacity based subsidies seen in Spain. Significantly in relation to ancillary services, this impacts the opportunity cost to wind farm operators choosing to sacrifice energy capture in order to provide an ancillary service. Energy-based subsidies increase this cost significantly making provision of many ancillary services unattractive (or making wind noncompetitive), whereas capacity-based subsidies mean that the opportunity cost depends on the wholesale value of energy only. The 6.3 GW of Spanish wind operating subsidy free in 2017 gives an insight into how market behaviour will change for subsidy free wind farms particularly in reserve markets. Barring any significant retrospective change in subsidy support regimes in GB, over $10 \mathrm{GW}$ of wind farms will lose their ROC and CfD subsidies in 2027/28, resulting in a marked increase in subsidy free wind capacity in GB.

In Spain, wind energy production, is monitored and controlled by the Renewable Energy Control Centre (CECRE). Every wind farm above $5 \mathrm{MW}$ is connected to CECRE, production and status data are refreshed every $12 \mathrm{sec}-$ onds and CECRE may instruct wind farms to operate at specific power levels. This allows wind output across the country to be coordinated. This is not the case in GB where different operators of wind farms have control rooms which act on instructions from the TSO.

Despite being an island, GB has a higher level of interconnection with Europe than Spain and has more ambitious plans to increase this capacity further. However, the $4 \mathrm{GW}$ of GB interconnection is HVDC (and therefore does not 
contribute to system inertia), and some links can represent the largest loss of infeed risk which the TSO must protect against, representing a significant cost.

\section{Balancing, Replacement Reserves and Wind Curtailment}

Balancing markets provide a competitive mechanism for re-dispatch actions taken by the transmission system operator to maintain the balance of supply and demand and manage network constraints in close to real time. They typically operate from gate closure of wholesale markets to delivery time. Gate closure is one hour ahead of delivery in both GB and Spain. In addition, a range of balancing reserve products are procured in advance to ensure that some minimum amount of energy is available for balancing. Replacement reserves operate on a similar time scale and are procured in order to be able to replace the loss of a large generation plant or interconnector. RR may also be activated to restore balancing reserves after they have been used.

In order to facilitate trading of variable generation closer to real time, gate closure has become later and settlement periods shorter. In 2002, gate closure in GB moved from 3.5 hours before the beginning of each settlement period to 1 hour [64], and today trading is permitted up to the beginning of each settlement period, although generator schedules are fixed at the BM's gate closure [65]. Various European institutions are debating targets of setting both gate closure and settlement period length to 15 minutes by the early 2020 s.

\subsection{Market Mechanisms: Spain}

In Spain, the RR product is defined as the maximum variation of power generation that a generating or pump storage unit can experience in 15 minutes. To participate in the RR market, plant must pass capability tests related with ramp response and TSO setpoint tracking [66]. This product is offered to the TSO in a day-ahead market with a gate closure at 11:00 pm [67]. Nevertheless, the bids in this market can be updated up to 60 minutes before delivery time when capacity is committed in other ID markets, and up to 25 minutes 


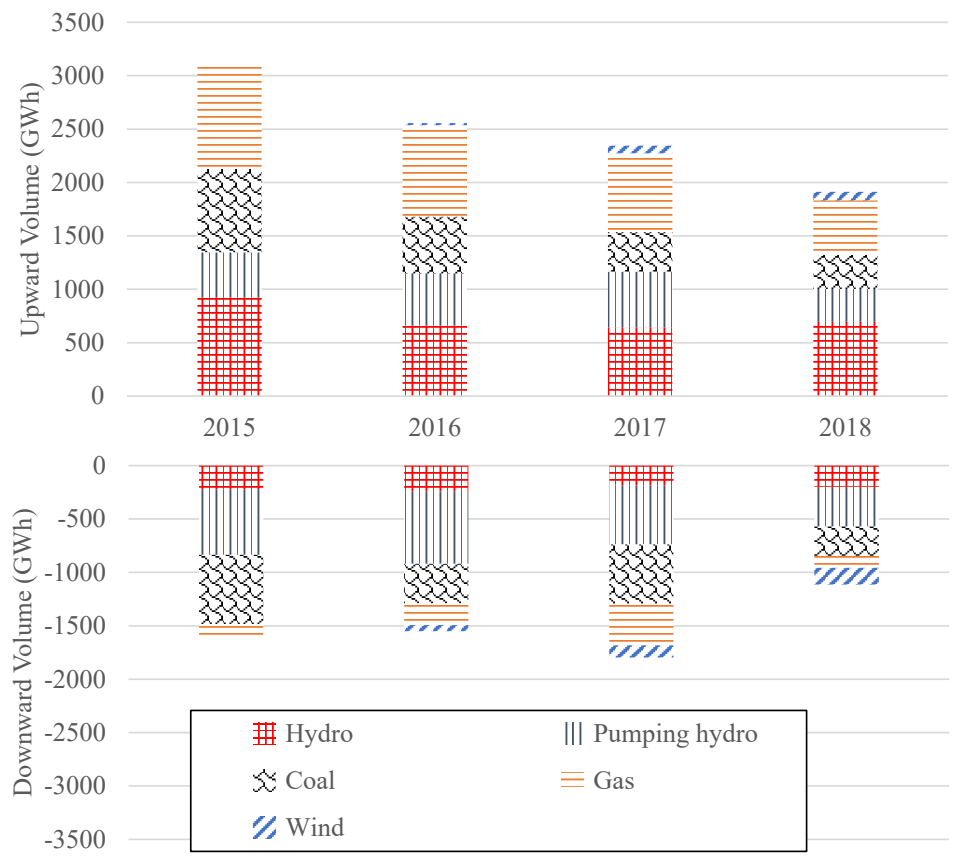

Figure 9: Spain RR upward and downward volumes by technology type; data: 11.

before delivery while Cross Border Balancing using Tertiary Reserves (BALIT) is not active [68. Bidding flexibility, jointly with the procurement of upward and downward directions separately, offers better conditions for wind energy to participate.

The contribution of wind energy to RR started on April $1^{\text {st }} 2016$ [10]. This participation increased progressively with wind providing $4.2 \%$ of upward and $14 \%$ of downward RR volumes in 2018 (see Figure 9). The largest hourly volumes were 788.9 MWh for upward, and -2500 MWh for downward.

Prices for upward and downward RR displayed an upward trend in recent years except in 2016 as shown in Figure 10. The upward RR prices are the highest of FRR and RR products with average values between 50 and $67 € / \mathrm{MWh}$. In contrast, downward energy has lower prices, ranging between 12 and 41 $€ /$ MWh. The decrease in 2016 corresponded to the participation of wind energy and particularly hydro in the first five months of the year, displacing higher 


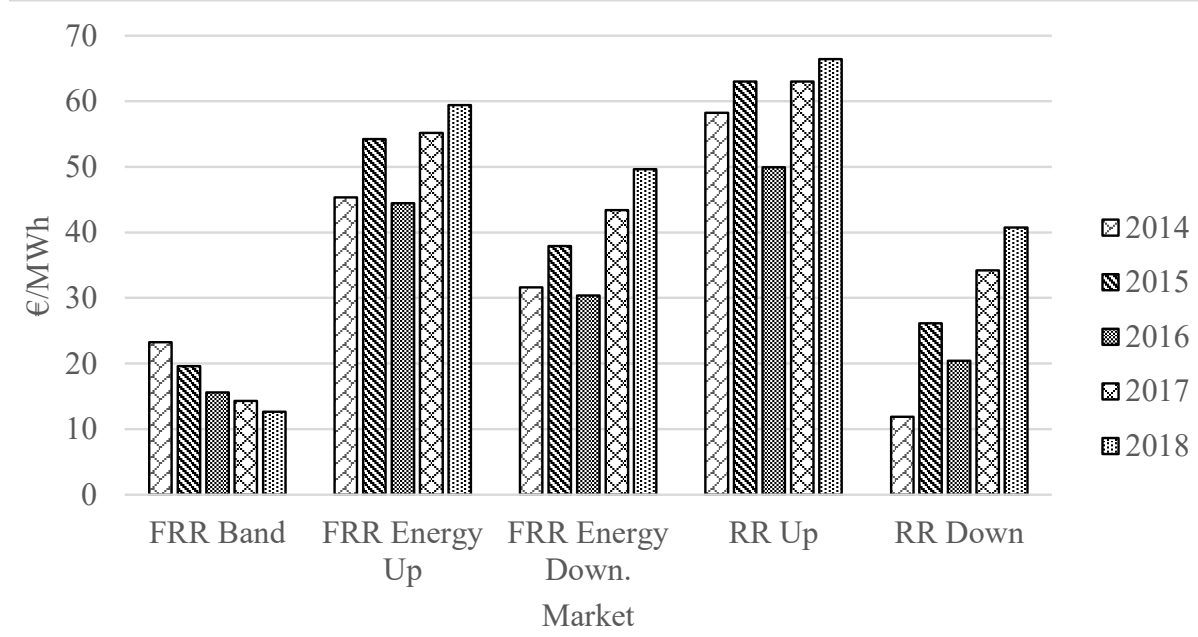

Figure 10: Spain FRR and RR market prices 2014-2018; data: 11.

bids of combined cycle plants [69].

\subsection{Market Mechanisms: $G B$}

In GB there are two main mechanisms for providing $\mathrm{RR}$; the $\mathrm{BM}$ which is a market with gate closure 1 hour before delivery and STOR which is contracted 3 months in advance but can be activated through the BM.

The balancing mechanism. The $\mathrm{BM}$ is a real-time market used by the TSO to balance supply and demand and create flexibility by part-loading plant. Another function of the BM is managing transmission network constraints by redispatching generation. Balancing parties (including wind farms) submit their final physical notifications (FPNs) to the TSO 1 hour before delivery along with offers to increase generation (or decrease demand) and bids to decrease generation (or increase demand).

The most active technology (by volume) in the BM is gas plant (CCGT plus OCGT) for both upward or downward actions (see Figure 11), wind has the next biggest share of downward volumes which is due to curtailment. Some of the gas plant actions are for energy balancing (including arbitrage) and some are for redispatch due to constraints. Wind curtailment is almost exclusively a result of 


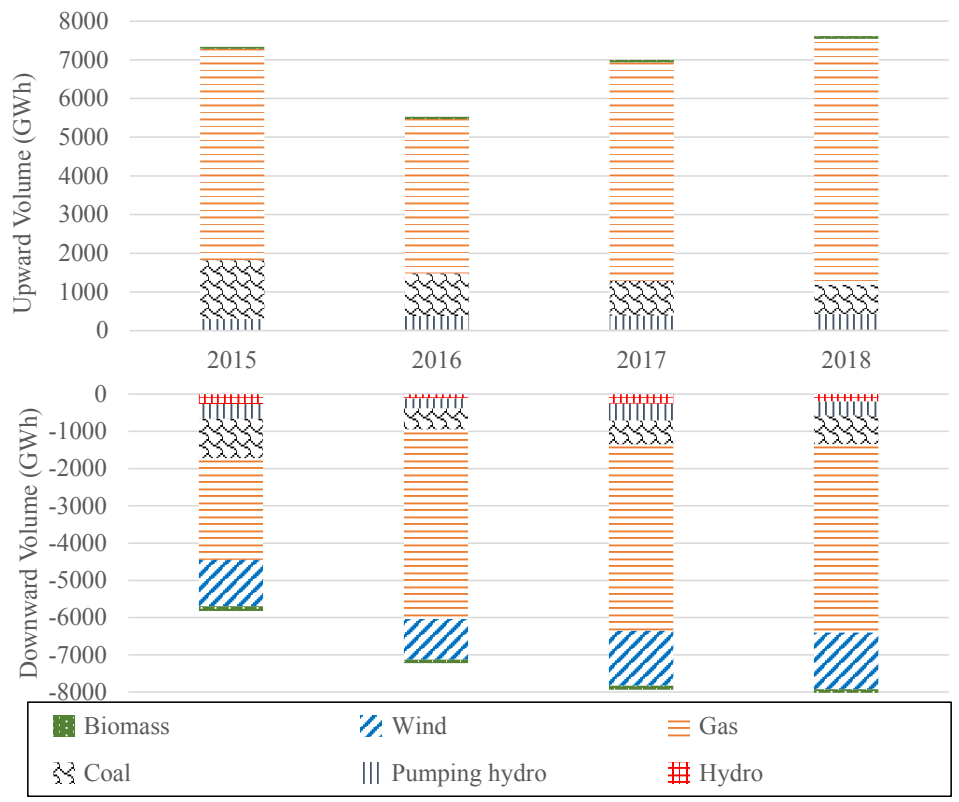

Figure 11: GB Volume of BM actions, including STOR activated via the BM, but not 'nonBM' STOR (which has significantly higher utilisation volumes than BM STOR); data: [51.

network constraints. This distinction is important, as energy balancing actions are used to calculate the system price (the imbalance price), whereas actions taken to resolve network issues are not included in determining the imbalance price.

STOR. The purpose of STOR is to provide replacement reserve up to the size of the most credible outage which in GB is $1320 \mathrm{MW}$ at present, expected to rise to $1800 \mathrm{MW}$ on completion of Hinkley Point C nuclear power station (under construction) [70]. The operation of Hinkley Point $\mathrm{C}$ is therefore expected to increase the demand for frequency response. However, on occasion it has been more economic (or even necessary for reasons related to the rate of change of frequency) for the TSO to reduce the maximum loss of in-feed, by curtailing the largest generator, than holding the large volumes of frequency response required to secure against the plant tripping.

Wind is not able to tender for STOR as it is contracted 3 months in advance. 
Procurement would need to move to day-ahead or closer for wind power forecast to be sufficiently accurate. STOR is an upward reserve product and would require wind to be curtailed/re-positioned to provide headroom if it was to enter this market. In order to provide upward reserve, wind farms would need to price this service at the combined value of wholesale and subsidy revenue, making wind uncompetitive with most other technologies. For example, CCGTs will pay around $£ 40 / \mathrm{MWh}$ (depending on gas price) to turn down as they save on fuel not consumed, whereas subsidised windfarms charge an average of $£ 70 /$ MWh to cover lost subsidy and additional operational costs.

\subsection{Curtailment: Spain}

In Spain, curtailments are included in technical restriction mechanisms and are resolved through a mandatory set point provided by the TSO. There are four sources of constraint resulting in curtailment of wind energy [71]:

- Congestion in the transmission and/or distribution networks

- System stability limits

- 'Non-integrable generation excess' - when load is lower than scheduled production

- Control tests - the TSO can instruct control centres to test set-point tracking capability

Curtailments to maintain system stability were more prevalent before 2010 as most wind turbines had not passed fault ride through certification [72]. Since 2011, congestion and non-integrable excess have been the main causes of curtailment. The participation of wind energy in balancing markets in the downward direction has reduced curtailments to very low levels. Curtailment is priced at $85 \%$ of the day-ahead market price for every hour and until 2014, FiTs were also reduced during curtailments as FiTs were based on generation volume. Since the change in the subsidies, the volume of wind curtailment has reduced significantly. This is due to the contribution of wind energy to RR and Imbalance 
Table 6: Spain Cost and volume of wind curtailment 2012-2017 ${ }^{1}$

\begin{tabular}{l|l|l|l|l|l|l|l} 
Year & $\begin{array}{l}\text { WE gen- } \\
\text { eration } \\
\text { (TWh) }\end{array}$ & $\begin{array}{l}\text { Load } \\
\text { (TWh) }\end{array}$ & $\begin{array}{l}\text { WE/ } \\
\text { Load } \\
\mathbf{( \% )}\end{array}$ & $\begin{array}{l}\text { WE Cur- } \\
\text { tailment } \\
\mathbf{( T W h )}\end{array}$ & $\begin{array}{l}\text { WE Curtail- } \\
\text { ment / WE } \\
\text { production } \\
\mathbf{( \% )}\end{array}$ & $\begin{array}{l}\text { WE Cur- } \\
\text { tailment } \\
\text { cost (m€) }\end{array}$ & $\begin{array}{l}\text { WE Cur- } \\
\text { tail- } \\
\text { ment } \\
\text { cost }\end{array}$ \\
\hline $\mathbf{2 0 1 2}$ & 48.1 & 251.7 & 18.0 & 0.12 & 0.25 & 3.23 & 26.91 \\
$\mathbf{2 0 1 3}$ & 54.3 & 246.2 & 21.2 & 1.16 & 2.14 & 7.19 & 6.20 \\
$\mathbf{2 0 1 4}$ & 50.6 & 243.5 & 19.9 & 0.52 & 1.02 & 2.77 & 5.33 \\
$\mathbf{2 0 1 5}$ & 48.1 & 247.2 & 17.9 & 0.05 & 0.12 & 1.44 & 28.85 \\
$\mathbf{2 0 1 6}$ & 47.7 & 249.2 & 18.2 & 0.09 & 0.20 & 1.96 & 12.72 \\
$\mathbf{2 0 1 7}$ & 46.9 & 252.2 & 18.5 & 0.05 & 0.11 & 0.81 & 42.01
\end{tabular}

${ }^{1}$ Wind Energy (WE) generation, load and curtailment data are from REE [73]

Management markets and the drop of wind energy generation in comparison with 2012 and 2013 (see Table 6). In contrast curtailment prices have risen as DAM prices are higher and, recently, there have not been $0 € / M W h$ periods in the DAM during low demand as described in Section 2.3

\subsection{Curtailment: $G B$}

Wind curtailment has risen $150 \%$ from 0.6 TWh in 2014 up to 1.5 TWh in 2018 (see Table 7) while wind generation has increased by $86 \%$ over the same period. The majority of this curtailment occurring at Scottish onshore wind farms due to the B6 boundary constraint which limits the export capacity from wind farms in Scotland to load centres in England. The percentage of curtailment compared to generation for 2015 to 2018 is around $4 \%$ excluding embedded generation. Wind bids are priced to cover both subsidy payments (they forgo when curtailed) and operational costs, however, historically there has been opportunistic pricing [74]. Most onshore wind farms receive 0.9 ROCs per MWh (valued between $£ 40-£ 50 / \mathrm{MWh}$ ) and bid around $£ 65 / \mathrm{MWh}$ to be curtailed. Offshore wind farms receive between 1.5 and 2 ROCs per MWh (depending on year of construction) and wind farms receiving CfDs were awarded strike prices of up to $£ 150 / \mathrm{MWh}$ (plus inflation indexation) in the first round 
Table 7: GB Cost and volume of wind curtailment 2014-2018

\begin{tabular}{|c|c|c|c|c|c|c|c|}
\hline Year & $\begin{array}{l}\text { WE Gen- } \\
\text { eration } \\
(\mathrm{TWh})^{1}\end{array}$ & $\begin{array}{l}\text { Load } \\
(\mathrm{TWh})^{2}\end{array}$ & $\begin{array}{l}\text { WE } \\
\text { Gen/ } \\
\text { Load } \\
(\%)\end{array}$ & $\begin{array}{l}\text { WE Cur- } \\
\text { tailment } \\
(\mathrm{TWh})^{1}\end{array}$ & $\begin{array}{l}\text { WE Curtail- } \\
\text { ment / WE } \\
\text { production } \\
(\%)\end{array}$ & $\begin{array}{l}\text { WE Cur- } \\
\text { tailment } \\
\text { Cost } \\
(£ m)^{1}\end{array}$ & $\begin{array}{l}\text { WE Cur- } \\
\text { tailment } \\
\text { Cost } \\
\text { (£/MWh) }\end{array}$ \\
\hline 2014 & 21.1 & 290.5 & 7.3 & 0.6 & 2.8 & 51 & 85.4 \\
\hline 2015 & 29.4 & 282.2 & 10.4 & 1.2 & 4.2 & 96.8 & 72.6 \\
\hline 2016 & 27.3 & 275.5 & 9.9 & 1.1 & 4 & 83.2 & 73.6 \\
\hline 2017 & 36.8 & 265.9 & 13.9 & 1.48 & 4 & 108 & 71 \\
\hline 2018 & 39.2 & 276.3 & 14.2 & 1.52 & 3.9 & 110.5 & 72.5 \\
\hline
\end{tabular}

${ }^{1}$ From Elexon BM Reports [51]. Does not include embedded wind.

${ }^{2}$ Based on National Grid GB demand data [75. Does not include demand met by embedded generation.

of auctions. This is reflected in the bid prices for offshore wind which are often over $£ 150 /$ MWh. Most of the large offshore wind farms are off the coast of England, on the demand side of the Scotland-England transmission constraint, therefore they are not curtailed to the same extent Scottish onshore wind farms.

The average bid price for wind farms in the BM between 2015-2017 along with the volume of curtailment for each wind farm is shown in Figure 12 In general, wind farms with lower bid prices are curtailed more often. Whitelee windfarm 5 , in East Renfrewshire (Scotland), has the highest curtailment by a large margin, partly because it has a relatively low bid price but also because it is large, at over $300 \mathrm{MW}$, and therefore can provide a lot of flexibility for a single instruction compared to instructing multiple smaller units. It is seen that few wind farms with average bid prices above $£ 90 /$ MWh are curtailed significantly, with the exception of Crystal Rig phase 2 wind farm ${ }^{6}$ in East Lothian (Scotland), which is likely to have been curtailed because of local constraints, although information published relating to the BM does not provide specific reasons for $\mathrm{BM}$ actions.

The BM provides a market for wind to be rewarded for flexibility close to

\footnotetext{
${ }^{5}$ BMU IDs: T_WHILW- $1 / 2$

${ }^{6}$ BMU ID: T_CRYRW-2
} 


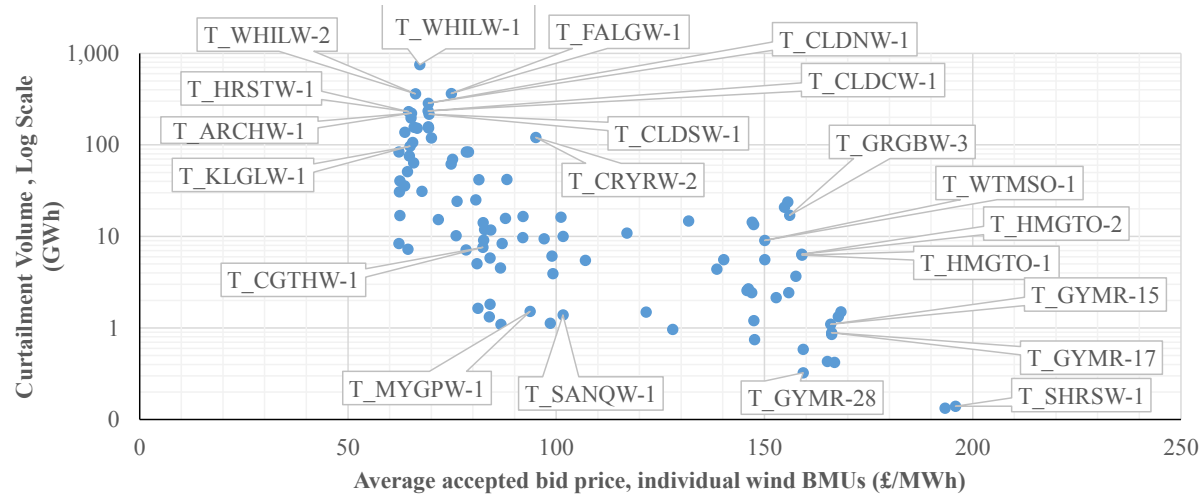

Figure 12: GB wind curtailment volume vs volume weighted average bids 2015-2018; data: 51] (Refer to BMUnits Register 51 for list of wind farm names).

delivery in GB. Licence conditions require that generators bid at prices they can justify during periods of transmission constraint [76. However, as the majority of onshore capacity is situated behind a transmission constraint, the costs of running the market can be high. The TSO has little choice but to turn down wind when there is a lack of transmission capacity between generation in Scotland and demand in the south of England. The cost of managing this constraint has provided an incentive for new network capacity such as the Beauly Denny power line (in Scotland) and recently commissioned Western Link (across the B6 boundary), which combined, cost consumers approximately $£ 2$ bn.

Wind FPN estimation error. Wind generators must submit final physical notifications (FPNs) of their expected output to the BM at gate closure 1 hour before each settlement period. If a bid is accepted in the BM (such as a curtailment instruction), the generator is compensated based on the volume of this bid, which is the difference between the FPN and their new set point. Therefore, in the case of wind farms, bid payments are based on forecast production rather than what would have actually been produced. Furthermore, a wind farm which is producing more than its FPN may be curtailed to its FPN without being compensated. In Figure 13, FPNs for wind BMUs are compared with actual metered generation, with periods including any curtailment removed. For the 


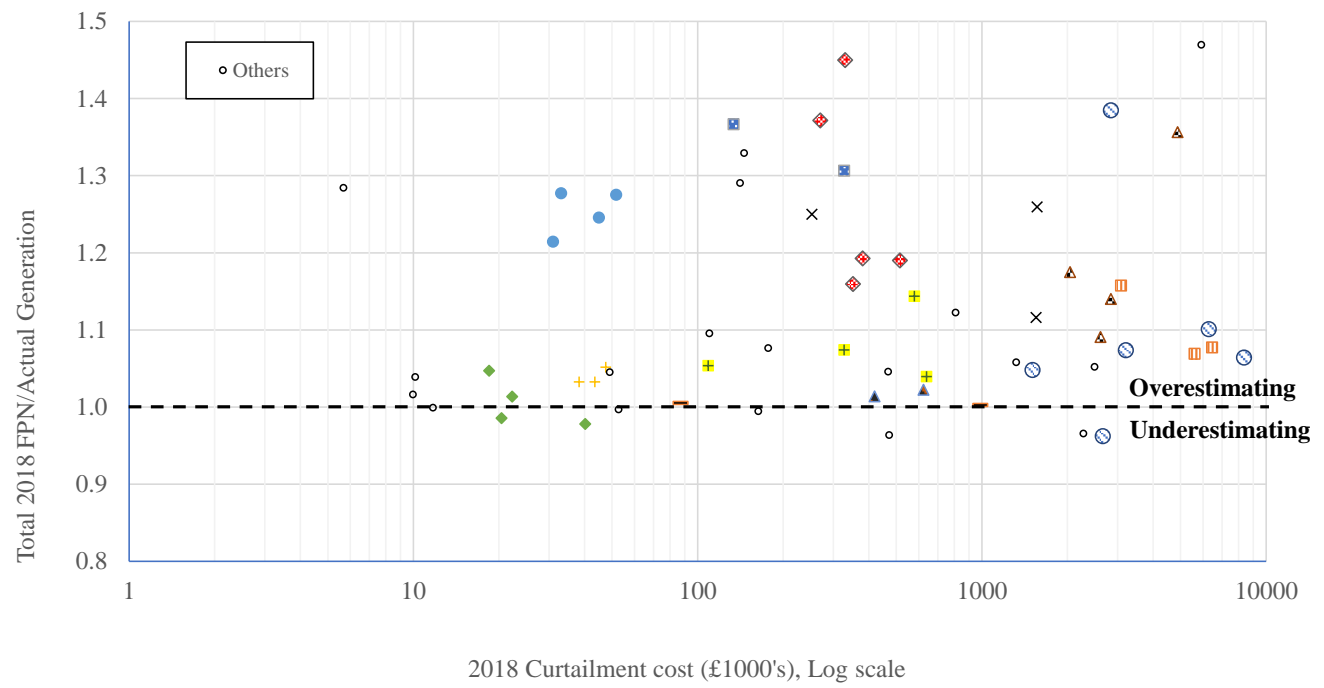

Figure 13: FPN divided by Actual Generation with Curtailment for GB wind farm BMUs by operator (each symbol represents an operator) 2018; data: [51;

majority of wind BMUs, FPNs are systematically higher than actual generation, which we estimate increases the total cost of curtailment by around $£ 6$ million/year $(\sim 7 \%)$ in 2017 and 20187. These costs are passed on to consumers via the balancing use of system charge.

In general, operators have similar FPNs estimation errors within their fleet; this is to be expected for wind farms that are split into several BMUs. There is a large variation in accuracy of FPNs between operators; some wind farms are using persistence forecasting with FPNs being based on metered output 2 hours earlier. This carries with it a greater error than forecasting methods used by others. The main operators of onshore Scottish wind farms, which are curtailed in the highest volumes in GB, generally overestimated their FPNs in 2018. This is estimated to have resulted in significant extra costs to consumers as they are

\footnotetext{
${ }^{7} \mathrm{FPN}$ error cost is estimated for each wind farm by binning average FPN errors (FPN minus metered 'Actual Generation') by power level for all settlement periods without curtailment, and assuming the same error during times of curtailment (for a years data). Outliers outwith 2 standard deviations are removed.
} 
curtailed in high volumes. Compensation based on 'power available' signals or capacity-based subsidy schemes could help reduce incentives for wind farms to bias their FPNs.

\subsection{Policy Recommendations}

Upward RR will not be attractive for wind unless the value of $R R$ exceeds the value of energy (wholesale plus subsidy). As more wind farms move to being subsidy free in GB post 2027, there is the possibility that wind farms will be able to bid much more competitively for providing upward reserve. In Spain, since 2014, the subsidies have been related only with investment and operational parameters, as a result wind farms offer energy to both wholesale and upward RR markets.

Lessons could be learned from Spain in moving from an energy-based subsidy to a capacity-based subsidy, or one could go further and combine capacity markets and CfD auctions into a firm capacity auction, as recommended in the Helm review [77]. If wind farms can adjust output without losing revenue then they will be more likely to participate in reserve and response markets. A further way GB could learn from Spain is to move from paid as bid remuneration for curtailment, to a price set by the TSO or regulator. Given that in GB the lost revenue to wind farms during curtailment is the subsidy revenue (they do not lose energy payments), the calculated remuneration should be enough to compensate wind farms for lost subsidy. This means that, for example, a wind farm could be compensated based on the number of ROCs they receive plus an amount to compensate for additional OPEX costs.

Gate closure in the Spanish RR market is a day-ahead but there are mechanisms to update bidding intraday until between 1 hour and 25 minutes before delivery. This provides flexibility and more accurate bids in the market. However, only a few market agents, with large enough aggregated capacity are allowed to bid. For both countries we recommend later gate closures and the aggregation of bids for wind farms to reduce forecasting error. 
A further policy recommendation for GB is to move from calculating curtailment remuneration from FPNs to a power available signal for each wind farm. We estimate that $6 \%$ of curtailment costs in 2017 and 2018 were a result of inflated FPNs, costing consumers approximately $£ 6$ million a year for curtailing energy that would never have been generated.

Two final recommendations are for more transparency from the TSOs with respect to reporting constraints, and that TSOs encourage more demand side participation in locations where constraints occur, such as in Scotland in GB, to reduce generation curtailment.

\section{Frequency Restoration Reserve}

Frequency Restoration Reserves (FRR) are needed to restore system frequency to nominal and restore FCR by responding to instructions to increase or reduce energy production/consumption within 2 minutes.

\subsection{Market Mechanisms: Spain}

FRR is an automatic service provided through the activation of a Master Regulator, usually owned by the TSO, and automatic generator control on units' regulators. This activation seeks to restore frequency and/or imbalances while respecting scheduled cross border trade programs [78]. The gate closure for the FRR market is at 5:30 pm for delivery the following day, and therefore wind farms rely on forecasts with lead-times of at least 6-30 hours.

The FRR product links the amount of upward and downward reserve that has to be provided in the so-called "regulation band". There is a single hourly marginal price for remunerating the reservation of this regulation band. This service is remunerated via two payments: availability and utilisation. The procurement of FRR is carried out day-ahead for the 24 hours of the next day. Exceptionally, FRR may also be procured during the day of operation when additional unexpected requirements are detected. FRR services are provided in so-called regulation zones and each zone is a balancing responsible party (BRP). 


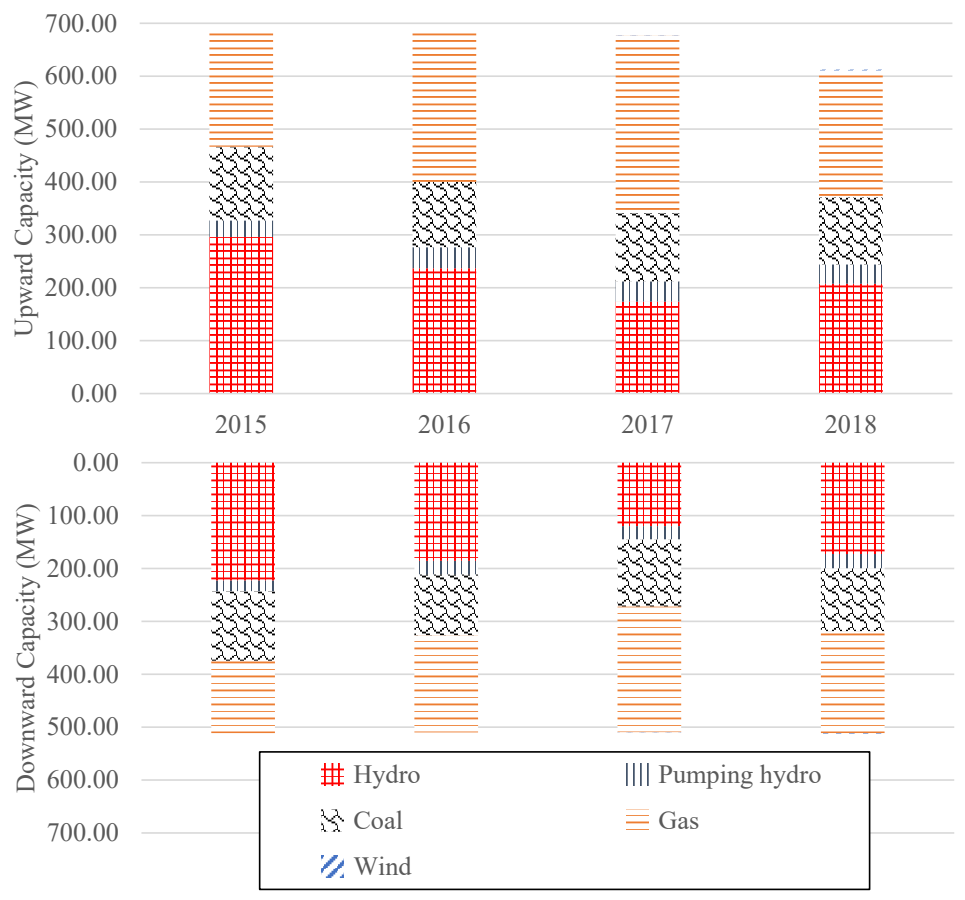

Figure 14: Spain FRR band capacity by technology type; data: 11

The aggregated installed capacity of all units within each regulation zone must be at least $300 \mathrm{MW}$. Consequently, wind energy units must aggregate to more than $300 \mathrm{MW}$ or be included in an aggregator's regulation zone portfolio to participate in the FRR market [68].

The average FRR band size in 2017 was 682 MW upward and 514 MW downward. Hydro and Gas represented more than $70 \%$ of the total assigned band power. The FRR utilisation prices for the full band are shown in Figure 10 . and availability prices were between 0.22 and $7.96 € / \mathrm{MW}$ with an average value of $1.43 € / \mathrm{MW}$ for the downward band. Utilisation volumes in 2017 reached 1203 MWh upward and $1212 \mathrm{MWh}$ downward with an average price of $55 € / \mathrm{MWh}$ and $43 € /$ MWh respectively [73]. The price trend for utilisation in recent years is similar to the RR market described in Section 3.1 .

Wind energy can now be included in a regulation zone and contribute to FRR. Nevertheless, only $1 \%$ of the total wind power capacity, $230 \mathrm{MW}$, is pre- 


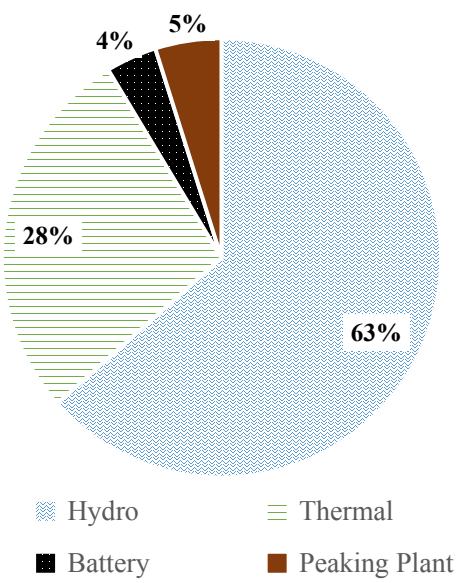

Figure 15: GB Tendered Frequency Restoration Reserve \% of capacity by technology, average for 2017 and 2018 combined; data: 75 .

qualified to participate in the FRR service due to difficulties passing capability tests and forecasting generation sufficiently accurately 6 to 30 hours-ahead. Its participation started in June 15th 2017 with $2 \mathrm{MW}$ in the band and $4 \mathrm{MWh}$ of utilisation. The most usual contribution to the FRR band is 1-2 MW with daily utilisation between 2 and 21 MWh for both downward and upward.

\subsection{Market mechanisms: $G B$}

In GB, the main source of FRR is an upward reserve service (known as Fast Reserve - FR) with a small number of providers, mainly hydro (see Figure 15, though some units can respond in the BM on these timescales, and Secondary Frequency Response also contributes. FR contracts are tendered on a monthly basis however most contracts are bilateral (non-tendered). In the 2017 financial year $£ 60 \mathrm{~m}$ was spent on non-tendered FR compared to $£ 13 \mathrm{~m}$ on tendered FR. Between 2016 and 2018 there has been between 270 MW to $400 \mathrm{MW}$ of tendered FR contracted. FR is utilised on average 5 mins at a time, 10 times a day 35]. Utilisation (MWh) of FR has been more than 4 times higher than STOR between 2016 and 2018 [47.

Wind generators do not currently provide FRR in GB due to tenders being at least a month in advance and the price being unattractive compared to potential 
energy and subsidy revenue. Wind can provide the ramping requirements for FRR but the tendering process would need to change to being closer to delivery (i.e DA or ID) to be within accurate forecasting windows to allow wind to reliably offer FRR.

\subsection{Policy Recommendations}

In Spain, FRR is procured a day in advance which has allowed wind to participate; this is an obvious first step for GB to take. In Spain, a new BRP only for wind energy is proposed in the short term. The main challenge is maintaining the band value for wind energy; one recommendation for overcoming this challenge is to add a highly aggregated wind energy BRP (more than $300 \mathrm{MW}$ ). In Spain, gate closure is a day-ahead; so forecasting horizons in excess of 12 hours are involved and there is no possibility to update bids as with RR. It is recommended to allow bids to be updated intraday to increase provision from wind closer to accurate forecasting horizons.

As with RR, the economics of subsidies and bidding behaviour would need to change for wind to competitively enter the market in GB. Subsidy free wind could be willing to bid at a 0 (or even negative) price to be re-positioned for offering FRR if the utilisation price was high enough to compensate for lost production revenue. If a wind farm is being curtailed, it could potentially offer FRR with a minimal availability and utilisation cost.

One possible way of hedging the risk from wind providing FRR is to allow mixed technology portfolio bids. For example a provider may have a fleet of wind farms across the country as well as some storage or thermal peaking plant. If they are allowed to bid into the market with a combined offer for the portfolio, they can dispatch peaking plant if called upon during a spell of low wind output, meaning they can guarantee a minimum FRR provision at all times. One caveat with this option is that the units (within a providers portfolio) may all need to be located within a certain region. When choosing FR providers, the TSO assesses locational constraints, therefore wind farms located behind constraints will not be the most reliable source of FR. 
Another policy suggestion for increasing the potential for new technologies (including wind) to provide FRR is to increase the liquidity of GB market by increasing the proportion of FR procured in short-term tenders relative to longterm contracts.

\section{Frequency Containment Reserve}

Frequency Containment Reserves are required to contain frequency within specified limits, particularly in the event of a large imbalance such as the sudden loss of a power plant or large demand. In Spain, the FCR mechanism is mandatory for all plants connected to the grid. Generators must provide 1.5 $\%$ of their production as FCR, which represents from 200 to $600 \mathrm{MW}$ depending on the demand. Some technologies, such as old wind farms and PV, rent FCR capability from conventional plants, mainly nuclear and thermal. There is limited information published on FCR in Spain, the remainder of this section focuses on GB where the TSO publishes information on both mandatory and commercial FCR.

In this section the participation of wind in FCR markets is considered in the context of the emerging need for new FCR products in GB and elsewhere as a result of changing characteristics of the power system. The increasing penetration of non-synchronous generation reduces system inertia and means that the system frequency will change more quickly when there is an imbalance between supply and demand. As a result, faster FCR is required to contain the frequency within limits of both the frequency deviation and rate of change of frequency.

\subsection{Market Mechanisms: GB}

In GB, the mechanisms for procuring frequency response are: Firm Frequency Response (FFR), Mandatory Frequency Response (MFR) and Enhanced Frequency Response (EFR). All large generators must have the capability to provide MFR as part of their connection agreement, including wind farms. All 
of these generators provide their capability and prices to the TSO on a monthly basis introducing competition, particularly on price. FFR is contracted monthly and participation is open to smaller generators ( $>1 \mathrm{MW})$ and Demand Side Flexibility (DSF). Low frequency response is categorised as primary and secondary, defined as active power response at 10s and 30s, respectively (see Figure 16) while high frequency response is only procured based on a 10s response time. Primary, secondary and high are all procured as both MFR and FFR. The EFR product requires active power response within 1s and has only been procured once in 2016 in a tender which resulted in contracts for 201 MW of EFR from 8 battery projects for 4 years. In the future, 1s response will be procured as part of the FFR process and possibly new mechanisms.

Historically, frequency response has been provided by coal, gas and hydro plant in GB, but with the closure of coal plants and cost reduction in battery technology this has changed dramatically in the past few years. Hydro and gas dominate the FFR market, particularly for large contracts, however a significant share of this market has been taken by DSF and battery participation in 2018 (see Figure 17) though typically for short-term contracts. This has resulted in large drop in FFR prices (dynamic primary) from over $£ 20 / \mathrm{MW} / \mathrm{h}$ to under $£ 10 / \mathrm{MW} / \mathrm{h}$. Wind is unable to participate in the FFR market as wind power forecasts are not reliable on month-ahead time scales.

\subsection{FCR from wind}

MFR is accessed by the system operator in close to real time to adjust FCR holding, typically from thermal generators which are already scheduled to be generating. The system operator may need to accept bids and offers in the BM in order to 're-position' MFR providers in order to create headroom/footroom for responding to frequency variations. Wind has historically not been used for MFR as the cost of repositioning to provide the headroom for primary and secondary MFR is high as it must compensate lost subsidy revenue compared to thermal plant which pay to turn down as doing so reduces fuel costs. Wind is however able to provide high MFR at competitive rates as no repositioning 


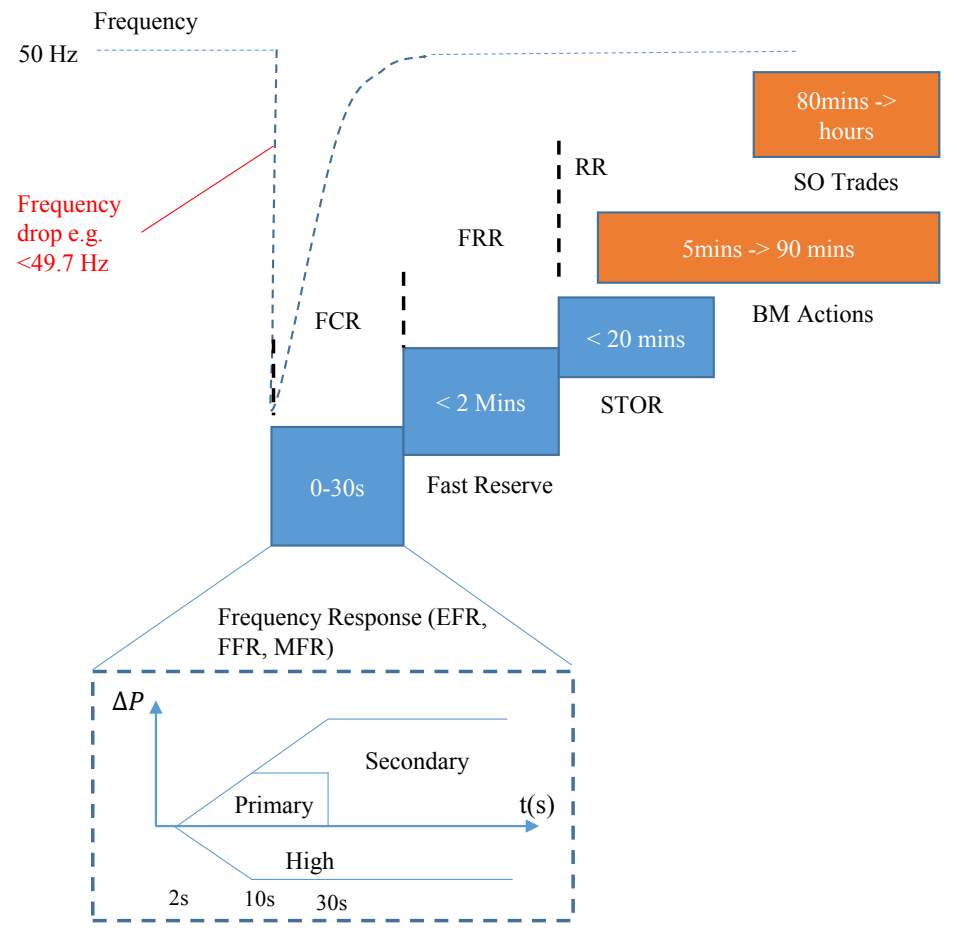

Figure 16: Timeline of post-fault response and reserve services in GB. The TSO aims to use dynamic frequency response and BM actions in pre-fault scenarios to maintain nominal frequency rather than consume services such as FR and STOR, which are meant as contingency actions. Based on data from [75]. 

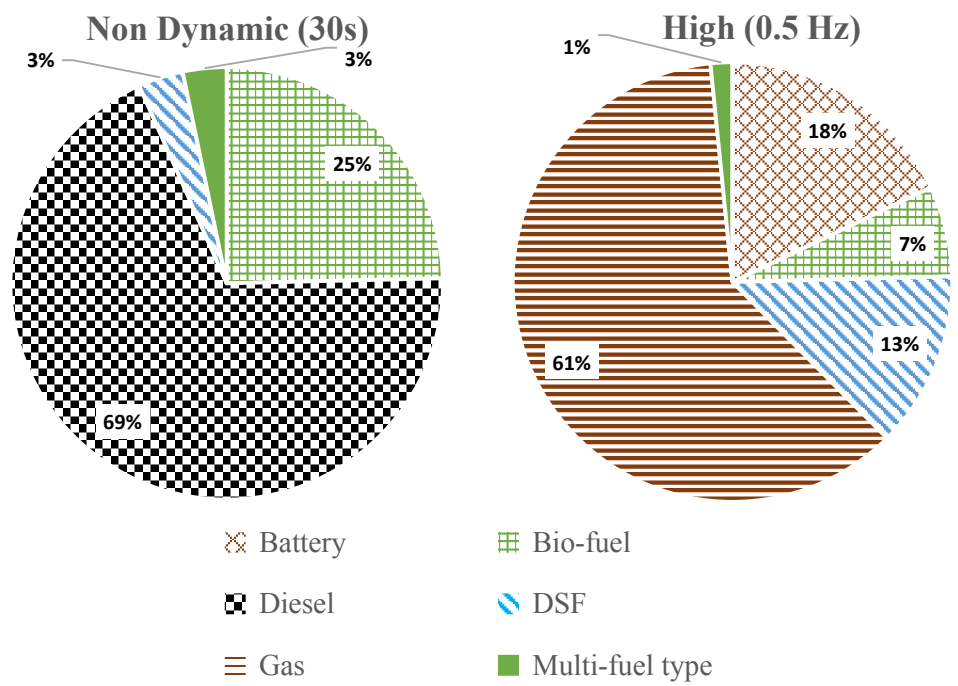

Figure 17: GB \% of tendered FFR capacity, by technology type 2018; data: 47.

is required to provide footroom.

The net-revenue for wind providing frequency response is the sum of the opportunity cost for not generating energy (if leaving headroom for primary and secondary response), the net-revenue accrued from delivering response energy, and the availability fee paid for providing the service. The opportunity cost associated with not generating is equal to the value of energy, including subsidy, if offering frequency response in a forward market, such as FFR; however, this cost is borne by the TSO in the case of MFR as headroom is created by partially curtailing the wind farm. When delivering the service, the net-volume of energy produced or not depends on the system frequency during the delivery period, and is typically very small. Wind farms that receive subsidy based on energy as measured by their export meter may therefore either benefit from additional revenue or suffer a loss due to reduced production. The revenue of a subsidy free wind farm, or a wind farm receiving a capacity-based subsidy would be unaffected. These are the potential costs which must be covered by the wind farm availability fee.

Therefore, offering primary and secondary response in a forward market is 
unappealing as the opportunity cost is large — over $£ 100 / \mathrm{MWh}$ for ROC and some CfD wind farms, or over $£ 50 / \mathrm{MWh}$ for subsidy free - compared to the value of the service which is around $£ 10 / \mathrm{MW} / \mathrm{h}$ today. Furthermore, this makes wind, even subsidy free wind, an expensive option for the system operator to access via MFR as they must re-position the provider and take other actions to maintain the energy balance.

However, wind can offer high-only frequency response at extremely competitive rates as the opportunity cost from energy revenue is zero and the possible loss of subsidy is small, though uncertain as it depends on frequency variations during the delivery period. Based on the past four years of the GB system frequency and a typical wind farm's response characteristic, we estimate that the average utilisation energy delivered by a wind farm would be $4.3 \%$ of available high MFR volume, i.e. a wind farm providing $10 \mathrm{MW}$ of high MFR for one hour would deliver 0.43MWh of response energy, on average. Assuming independence of utilisation and being selected to provide the service, the break-even holding fee for a typical ROC wind farm would be $£ 2.03 / \mathrm{MW} / \mathrm{h}$, though the cost in the worst $1 \%$ of settlement periods would be in excess of $£ 7 / \mathrm{MW} / \mathrm{h}$ (based on 1 ROC/MWh at $£ 47.20 /$ ROC). This makes even subsidised wind competitive with conventional generators which typically offer mandatory high frequency response in the $£ 3-5 / \mathrm{MW} / \mathrm{h}$ range, and subsidy free wind can participate with no marginal cost.

\subsection{Bidding behaviour of wind in MFR market}

Since August 2018 some wind farms (particularly Whitelee) have been bidding in to the MFR market with a competitive holding price of $£ 5.29 / \mathrm{MW} / \mathrm{h}$ (and below) for High and 0 bids for Primary and Secondary MFR. This has

resulted in a large increase in utilisation of wind farms in the MFR market (see Figure 18, and the analysis above suggest that this price is conservative and that further price reduction is possible. However, most wind farms still price themselves out of the market showing a reluctance to participate. This is due, at least in part, to changes in operational practice being viewed as an unknown 


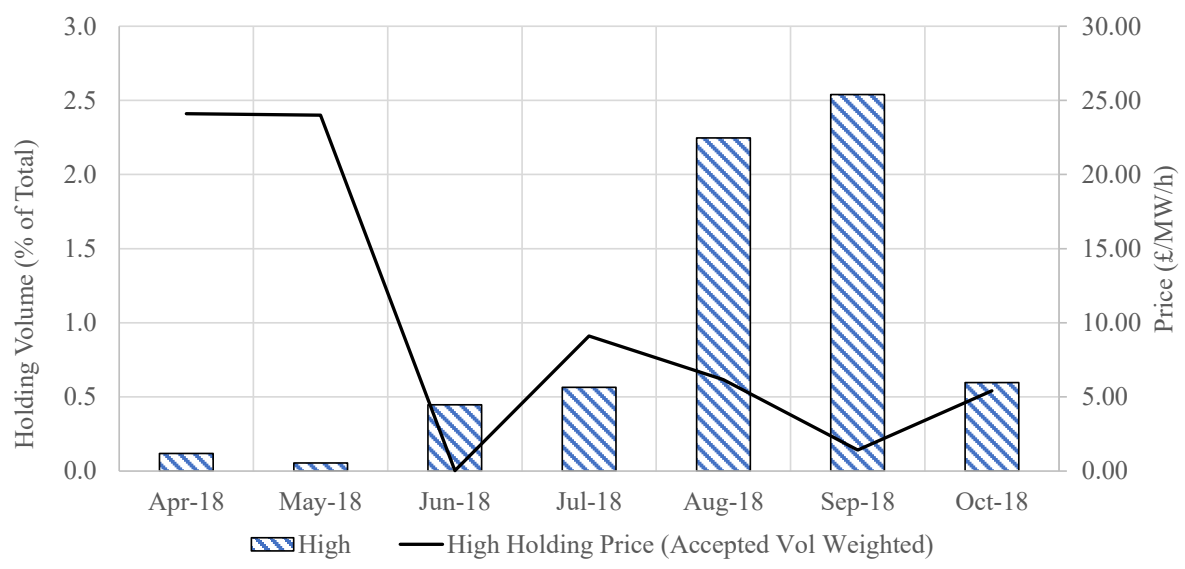

Figure 18: MFR Holding Volumes and volume weighted price wind farms providing mandatory high frequency response in GB; data: 75 .

risk by the consortia and financial institutions which own much of the wind fleet in GB.

\subsection{Policy Recommendations}

New mechanisms for procuring FCR are required to both meet emerging needs of system operators for faster response, and to increase competition by removing barriers to entry from technologies that rely on short-term forecasts. In GB, the capability of wind to provide MFR has been demonstrated with a market that allows them to participate, with only lost subsidy revenue discouraging wider involvement. If planned subsidy free wind farms participate in MFR they could apply significant price pressure on the market for high frequency response. It is recommended that the Spanish TSO publish more information on the provision of FCR and the technologies involved. It may be that a competitive market could be beneficial for increasing the provision of FCR by new technologies in Spain.

A further recommendation, which applies to all reserve products, is to maximise the potential for stacked offerings where doing so does not compromise the ability to deliver on any individual service in the stack. If a wind farm is re-positioned to provide one service (e.g. FCR) there is potential that this 
will allow them to provide another service (e.g. upward RR). By stacking their ancillary service provision, the revenue from provision of reserve could outweigh the lost income from repositioning.

An auction mechanism for FCR is being trailed in GB from mid-2019 and is discussed in section 6.3 .

\section{Future Trends}

A large number of national and international initiatives have been established to further integrate renewables in power systems, many of which focus on ancillary services. In this section we briefly review those of most relevance to wind.

\subsection{New pan European RR market}

A major development in the RR markets in Europe is the implementation of European project TERRE (Trans European Replacement Reserves Exchange) [79] which initially will involve GB, France, Italy, Portugal, Spain and Switzerland. TERRE is planned to be operational from December 2019 providing a trans-European reserve market with 15 minute products and settlement periods [80. The TERRE reserve market will run in parallel to the existing GB BM with BM participants having the option to participate in either market [81. The TERRE reserve market will be paid as cleared and it is not envisaged that subsidised wind in GB will participate to a large extent. Prices in the TERRE RR market would have to be higher than the subsidy to compensate wind generators sufficiently for lost revenue if they were to provide downward reserve for countries with energy based subsidy.

In Spain, under the TERRE RR market mechanism, wind energy could bid using short horizon forecasts, as this market uses the remaining cross-border capacity after the last ID market. In addition, the activation (30 min) and delivery (5-15 min) periods are compatible with the capability tests passed by RR qualified wind power capacity. However, the low interconnection capacity 
between Spain and the rest of Europe will limit the volumes provided by Spain in the TERRE RR market.

\subsection{New FRR markets in the continental Europe synchronous area}

Two new platforms are proposed for coordinated FRR markets in the European synchronous area: the PICASSO project for automatic FRR, and the MARI project for manual FRR in TSO-TSO exchange. The implementation of the platforms is expected by the end of 2021. The PICASSO project has 14 TSO members and the MARI project has 25 TSO members in the continental Europe and Nordic areas. The Spanish TSO, REE, is a member of both projects. The characteristics of both mechanisms are still undefined but full activation time is proposed to have no impact on offered FRR capacity for non-thermal units, particularly wind units, in the technical and economical assessment [82]. The gate closure in both cases is proposed at 25 minutes before real time, providing good conditions for wind energy bidding. It is recommended that highly aggregated wind energy bids should be allowed in these markets in order to increase participation, as proposed in Section 4.3 .

\subsection{Future trends in GB FCR Markets}

A new range of FCR products is being developed in GB including new products based on 1-second response and procurement via a short-term paid-asclear auction mechanism. The new products and procurement mechanism are designed to facilitate participation from a wider range of technologies, particularly those that rely on short-term forecasts to bid effectively such as wind, solar and DSF. Furthermore, more frequent procurement and short delivery periods mean that swings in the relative value of energy and FCR services can be exploited by market participants making the market more efficient and delivering consumer value. For example, during periods of high wind and solar production and low demand, energy prices are depressed and accessing FCR services from out-of-merit thermal plant can be expensive making wind competitive in the FCR market. Such situations are expected to become more frequent as the 
share of renewables grows in the future. The risk of non-delivery due to forecast errors is still an issue for wind, solar and DSF, even in day-ahead FCR markets. This challenge would be alleviated if there was a liquid market for secondary trading, and/or if participation was possible on a portfolio basis.

There is no immediate need for faster FCR products in the European synchronous area as the system inertia relative to the largest possible loss of infeed is much higher; however, as the penetration of non-synchronous generation increases regional requirements for faster response services may emerge.

\subsection{Other Ancillary Services}

This paper has focused on response and reserve services, but it should be noted that wind turbines and farms are capable of providing a wide range of other ancillary services, including reactive power and voltage control, and potentially even black start. Wind turbines connected to the system via power electronic converters can produce or consumer reactive power even when the wind is not blowing, for example. And in black out situations it would be desirable to make use of wind energy as well as frequency regulation and voltage control from wind farms to accelerate the restoration process [83, 84, 85].

\subsection{Strategic Participation in Multiple Energy and Ancillary Service Markets}

As wind farms gain access to new markets, new opportunities for strategic bidding and stacking services will emerge, as witnessed for battery energy storage. Generators may hedge between energy and one or more AS markets, depending on the relative price of services and possible costs for adjustment or non-delivery, as has been studied in [86], for example. This ability may be enhanced by participating as part of an aggregation of resources or 'virtual power plant', as in 87. While we have recommended changes to AS market arrange-

ments to increase access for wind, it is clear that generators will also have to innovate in order to take full advantage of new opportunities. 


\section{Conclusions and Policy Recommendations}

Modern wind turbines are highly controllable and have the capability to provide a wide range of ancillary services. We have reviewed and analysed the participation of wind in reserve and response markets in GB and Spain, making a number of specific policy recommendations. In general, participation is only possible when markets are run close to delivery, ideally day-ahead or shorter when wind power forecasts are reasonably accurate. Furthermore, participation is only economic to wind generators when the value of the service is greater than the energy and subsidy revenue that could otherwise be produced. Short delivery periods aligned with wholesale energy settlement periods would enable the market to respond to variations in the relative value of energy and ancillary services. As subsidy schemes come to an end, we expect to see the participation of wind in reserve and response markets increase as doing so becomes commercially attractive. Where new subsidy schemes are being considered, capacity-based mechanisms should be favoured if encouraging wind's participation in reserve and response markets is a priority.

Recent progress has been made in GB where provision of FCR from wind has been increasing and trials of a new FCR auction are planned which should facilitate participation from wind. However, in many areas the market structures and subsidy regimes in GB are hampering participation. To this end the following policy recommendations are made:

- A capacity (rather than energy) based subsidy would make the economics of wind providing reserve much more attractive as wind farms would not lose subsidy revenue when repositioning to provide reserve. This has been discussed in Sections 3.5 and 4.3

- The current policy of curtailment payments based on operator-submitted notifications of expected generation (FPNs) should be revised to incentivise accuracy rather than over-estimation (as discussed in Section 3.4. Options include penalising operators who systematically overestimate fu- 
ture production, basing curtailment payments on 'power available' signals, and capacity-based subsidy schemes.

- Enabling provision of RR, FRR and FCR on a portfolio basis (either multiple wind farms or technologies) as discussed in Section 4.3 and/or the existence of a liquid market for secondary-trading would help manage forecast uncertainty and support participation.

- Improving the controllability of wind and other variable resources, via a dedicated control centre along the lines of CECRE in Spain or the new distributed resource desk in the National Grid control room, would enable the TSO to operate the transmission system more cost effectively.

Spain has reached an important milestone in the participation of wind energy in RR but the volume has been reduced especially in the downward direction. The prices have an upward trend in energy for both FRR and RR, and a marked downward trend in FRR band especially in the downward direction. In contrast, FRR participation has been almost negligible as the pre-qualified capacity is less than the minimum BRP value and gate closure time is at DA time. In this context, the following recommendations are made the to TSO and wind farm owners:

- Improve FRR participation through a gate closure near real time and with the provision of a BRP totally formed by wind energy as discussed in Section 4.3

- Improve the coordination of bids between RR and Imbalance Management markets to take advantage of intraday bidding in the RR market taking advantage of the flexible bidding described in Sections 3.1 and 3.5

- Analyse the possible saturation of the downward RR market with greater amounts of qualified wind energy (Section 3.1), as more than $3 \mathrm{GW}$ of new wind capacity is soon to be installed. 
- Provide a competitive FCR mechanism to increase the volume of renewable energy (discussed in Section 5.4), especially wind energy.

In general, a more holistic approach is required to ensure sufficient generation capacity and reserve are available. The current arrangement of having a capacity market running separately to ancillary service markets, could be resulting in inefficient investment in carbon intensive fossil fuel generators. Energy and ancillary service markets need to be more flexible, and adapt to the rapidly changing generation/demand mix, rather than making long term contracts months in advance.

All the policy recommendations made in this work are aimed enabling greater participation from wind farms in frequency response and reserve markets. Not only could this support continued growth in installed wind capacity by providing new revenue streams at a time when subsidies are being reduced [12], but it is likely to be an economic necessity in power systems that frequently operate with high instantaneous wind penetration.

\section{Acknowledgements}

Calum Edmunds is supported by the EPSRC Centre for Doctoral Training in Wind and Marine Energy Systems (EP/G037728/1) and Jethro Browell by an EPSRC Innovation Fellowship (EP/R023484/1). This work was partially funded by the Spanish "Ministry of the Economy and Competitiveness" and the European Union (FEDER Funds), under the project ENE2016-78214-C2-1R. The authors would like to thank Graeme Hawker, Simon Gill, Susan Brush and Rosemary Tawn for internally reviewing the paper.

EPSRC Data Statement: All data produced by this research is contained within the paper and supplementary materials. GB BM data is courtesy of Elexon Balancing Mechanism Reporting Service and can be found at www.bmreports.com. GB frequency data and details of mandatory and firm frequency response capabilities, prices and tender results can be found at www.nationalgrideso.com. 
Spain BM data is courtesy of Red Eléctrica de España and can be found at www.esios.ree.es.

\section{References}

[1] P. Heptonstall, R. Gross, F. Steiner, UKERC, The costs and impacts of intermittency - 2016 update, http://www.ukerc.ac.uk/publications/ the-costs-and-impacts-of-intermittency-2016-update.html, [accessed 31/01/2019] (February 2017).

[2] Imperial College London and Pöyry, Roadmap for Flexibility Services to 2030, report to the Committee on Climate Change (UK) (May 2017).

[3] National Grid, System Operability $\quad$ Framework, https://www.nationalgrideso.com/insights/ system-operability-framework-sof, [accessed 20/01/2019] (November 2016).

[4] M. Joos, I. Staffell, Short-term integration costs of variable renewable energy: Wind curtailment and balancing in Britain and Germany, Renewable and Sustainable Energy Reviews 86 (August 2017) (2018) 45-65.

[5] P. J. Vogler-Finck, W. G. Früh, Evolution of primary frequency control requirements in Great Britain with increasing wind generation, International Journal of Electrical Power and Energy Systems 73 (2015) 377-388.

[6] National Infrastructure Commission (NIC), Smart Power, https://goo. gl/LKT7Fa, [accessed 31/01/2019] (March 2016).

[7] E. Rosales-Asensio, D. Borge-Diez, J.-J. Blanes-Peiró, A. Pérez-Hoyos, A. Comenar-Santos, Review of wind energy technology and associated market and economic conditions in Spain, Renewable and Sustainable Energy Reviews 101 (2019) 415-427. 
[8] L. Ziegler, E. Gonzalez, T. Rubert, U. Smolka, J. J. Melero, Lifetime extension of onshore wind turbines: A review covering Germany, Spain, Denmark, and the UK, Renewable and Sustainable Energy Reviews 82 (2018) $1261-1271$.

[9] Asociación Empresarial Eólica, Eólica 18, Tech. rep., AEE (2018).

[10] S. Martín-Martínez, A. Lorenzo-Bonache, A. Honrubia-Escribano, M. Cañas-Carretón, E. Gómez-Lázaro, Contribution of wind energy to balancing markets: The case of spain, Wiley Interdisciplinary Reviews: Energy and Environment 7 (5) (2018) e300.

[11] REE, ESIOS. Informaciǿn de mercados (2019), https://www.esios.ree. es/, [accessed 12/01/2019].

[12] K. Skytte, L. Bobo, Increasing the value of wind: From passive to active actors in multiple power markets, Wiley Interdisciplinary Reviews: Energy and Environment (2018) e328.

[13] D. Fraile, V. Charbonnier, The ten commandments of the wind industry on balancing markets, Tech. rep., Wind Europe (2016).

[14] Wind-Vision, ELIA, Eneco, ENERCON, Delivery of downward aFRR by wind farms, Tech. rep., ELIA (2015).

[15] P. Sorknæs, A. N. Andersen, J. Tang, S. Strøm, Market integration of wind power in electricity system balancing, Energy Strategy Reviews 1 (3) (2013) 174-180.

[16] TWENTIES Project, Transmission system operation with a large penetration of wind and other renewable electricity sources in electricity networks using innovative tools and integrated energy solutions, Final Report - Short Version, Tech. rep. (2013).

[17] S. Brauns, M. Jansen, D. Jost, M. Siefert, M. Speckmann, M. Widdel, Regelenergie durch windkraftanlagen, Tech. rep., Abschlussbericht IWES 
Fraunhofer, Bundesministeriums für Umwelt, Naturschutz, Bau und Reaktorsicherheit, Berlin (2014).

[18] R. Mackensen, Y. Saint-Drenan, D. Jost, R. Fritz, N. Asanalieva, M. Widdel, et al., Regelenergie durch wind- und photovoltaikparks, Tech. rep., Abschlussbericht IWES Fraunhofer, Bundesministeriums für Umwelt, Naturschutz, Bau und Reaktorsicherheit, Berlin (2017).

[19] S. Kirrmann, Kombikraftwerk 2. provision of balancing power from renewable energy sources, Tech. rep., German Renewable Energies Agency, Berlin (2017).

[20] REE, Wind on the grid (2009), https://ses.jrc.ec.europa.eu/ windgrid [accessed 23/01/2019].

[21] Ørsted, Press release - DONG Energy wind farm demonstrates frequency response capability (27 September 2016), https://goo.gl/vaF8my, [accessed 25/01/2019].

[22] National Grid ESO, Enhanced Frequency Control Capability (EFCC), https://www.nationalgrideso.com/innovation/ projects/enhanced-frequency-control-capability-efcc, [accessed $31 / 01 / 2019]$.

[23] C. Gerbaulet, C. Lorenz, Wind providing balancing reserves-An application to the German Electricity System of 2025, Tech. rep., DIW Berlin, Discussion Paper 1655, Berlin, Germany. (2017).

[24] S. Siniscalchi-Minna, M. De-Prada-Gil, F. D. Bianchi, C. OcampoMartinez, B. D. Schutter, A multi-objective predictive control strategy for enhancing primary frequency support with wind farms, Journal of Physics: Conference Series 1037 (3) (2018) 032034.

[25] A. D. Paola, D. Angeli, G. Strbac, Scheduling of wind farms for optimal frequency response and energy recovery, IEEE Transactions on Control Systems Technology 24 (5) (2016) 1764-1778. 
[26] S. Siniscalchi-Minna, F. D. Bianchi, M. De-Prada-Gil, C. OcampoMartinez, A wind farm control strategy for power reserve maximization, Renewable Energy 131 (2019) 37 - 44.

[27] S. S. Reddy, B. Panigrahi, R. Kundu, R. Mukherjee, S. Debchoudhury, Energy and spinning reserve scheduling for a wind-thermal power system using cma-es with mean learning technique, International Journal of Electrical Power and Energy Systems 53 (2013) 113 - 122.

[28] B. D. H. Kiran, M. S. Kumari, Demand response and pumped hydro storage scheduling for balancing wind power uncertainties: A probabilistic unit commitment approach, International Journal of Electrical Power and Energy Systems 81 (2016) $114-122$.

[29] S. Ataee, H. Bevrani, Improvement of primary frequency control by inertial response coordination between wind and conventional power plants, International Transactions on Electrical Energy Systems 27 (8) e2340, e2340 ETEP-16-0278.R3.

[30] Baringa, Negative pricing in the GB wholesale electricity market (Report for DECC) (2015).

[31] M. Bajwa, J. Cavicchi, Growing evidence of increased frequency of negative electricity prices in us wholesale electricity markets (2017).

[32] A. Khoshrou, A. B. Dorsman, E. J. Pauwels, The evolution of electricity price on the german day-ahead market before and after the energy switch, Renewable Energy 134 (2019) 1 - 13.

[33] ENTSO-E, European Commission Regulation (EU) 2017/1485 (2017).

[34] REE, Boletín mensual. Diciembre 2018 (12/2018).

[35] National Grid, Electricity Ten Year Statement 2017.

[36] Ofgem, Electricity Generation Mix by quarter and fuel source (2017), https://goo.gl/pxkUZk. [accessed 31/01/2019]. 
[37] Department for Business Energy and Industrial strategy (BEIS), UK Energy Statistics 2017 and Q4 2017 Statistical Press Release (March 2018).

[38] P. Rodilla, C. Batlle, Empirics of intraday and real-time markets in europe: Spain.

[39] REE, ESIOS. Unidades de programaciín (2018), https://www.esios.ree. es/es/unidades-de-programacion, [accessed 12/01/2019].

[40] Asociación Empresarial Eólica, Eólica 2016, Tech. rep., AEE (2016).

[41] Operador del Mercado Electrico Iberico Polo Español S.A, Resultados del mercado (2019), http://www.omie.es/inicio, [accessed 23/01/2019].

[42] Ofgem, Wholesale Market Indicators (2017), https://goo.gl/WNrC5S, [accessed 15/01/2019].

[43] Elexon, Final Modification Report P344 Project TERRE implementation into GB market arrangements (2018).

[44] OpenStreetMap contributors, Electrical Infrastructure map retrieved from https://planet.osm.org, https://www.openstreetmap.org, [accessed 20/01/2019].

[45] R. Garrett, Open Infrastructure Map, https://openinframap.org/ about.html, [accessed 23/01/2019].

[46] Department of Business, Energy and Industrial Strategy (BEIS), Renewable Energy Planning Database (December 2018), https://goo.gl/ Cs21NV, [accessed 20/01/2019].

[47] National Grid, Monthly balancing services summaries (MBSS) (March 2016 - 2018).

[48] APX GROUP, EPEX Spot Market, https://www.apxgroup.com/, [accessed 23/01/2019]. 
[49] Nord Pool, Europes Leading Power Market, http://www.nordpoolspot. com/About-us/, [accessed 31/01/2019].

[50] Nord Pool Spot, Nordpool N2EX FTP site with DA, ID and Spot Market Data., ftp://n2ex.nordpoolspot.com/Intraday/, [accessed $23 / 01 / 2019]$.

[51] Elexon, Balancing Mechanism Reports Online, https://www.bmreports. com/, [accessed 30/01/2019].

[52] Asociación Empresarial Eólica, Eólica 17, Tech. rep., AEE (2017).

[53] Ministerio de Industria, Energy and Tourism, RD 413/2014, https://www. boe.es/buscar/doc.php?id=BOE-A-2014-6123, [accessed 10/02/2019].

[54] Ofgem, Ofgem Renewables and CHP Register, https://www. renewablesandchp.ofgem.gov.uk/, [accessed 31/01/2019].

[55] Low Carbon Contracts Company, CFD Register, https://www. lowcarboncontracts.uk/cfds, [accessed 23/01/2019].

[56] HMG Government, Delivering Clean Growth: Progress Against Meeting Our Carbon Budgets - The Governments Response to the Committee on Climate Change (2018).

[57] J. C. Smith, D. Osborn, R. Zavadil, W. Lasher, E. Gómez-Lázaro, A. Estanqueiro, et al., Transmission planning for wind energy in the United States and Europe: status and prospects, Wiley Interdisciplinary Reviews: Energy and Environment 2 (1) (2013) 1-13.

[58] REE, Electricity interconnections: a step forward towards a single integrated European energy market (2012), https://www.ree.es/sites/ default/files/electricity_interconnections_eng_2.pdf. [accessed $25 / 01 / 2019]$.

[59] D. Huertas-Hernando, H. Farahmand, H. Holttinen, J. Kiviluoma, E. Rinne, L. Söder, et al., Hydro power flexibility for power systems with 
variable renewable energy sources: an iea task 25 collaboration, Wiley Interdisciplinary Reviews: Energy and Environment 6 (1).

[60] Department for Business Energy and Industrial strategy (BEIS), Digest of UK Energy Statistics (DUKES): Chapter 5 Electricity (2018).

[61] M. Nedd, K. Bell, C. Booth, Containing loss risk in a low inertia gb power system, in: 18th Annual Conference of the International Conference on Environmental and Electrical Engineering, IEEE, 2018.

[62] National Grid, Electricity Ten Year Statement 2018, https://www.nationalgrideso.com/insights/ electricity-ten-year-statement-etys, [accessed 23/01/2019].

[63] M. Petitet, M. Perrot, S. Mathieu, D. Ernst, Y. Phulpin, Impact of gate closure time on the efficiency of power systems balancing, Energy Policy 129 (2019) 562-573.

[64] Elexon, Modification Report P012 - Reduction of gate closure from 3.5 hours to 1 hour (2012).

[65] Elexon, Modification Report P342 - Change to Gate Closure for Energy Contract Volume Notifications (2016).

[66] REE, Criterios para participar en los servicios de ajuste del sistema y se aprueban determinados procedimientos de pruebas y procedimientos de operación (2015), https://goo.gl/8USUHJ, [accessed 23/01/2019].

[67] REE, P.O. 7.3 - Regulación terciaria (2015), https://www. ree.es/sites/default/files/01_ACTIVIDADES/Documentos/ ProcedimientosOperacion/RES_VAR_20151218_Participacion_en_ servicios_de_ajuste_y_aprobacion_P0s.pdf, [accessed 10/02/2019].

[68] C. Fernandes, P. Frías, J. Reneses, Participation of intermittent renewable generators in balancing mechanisms: A closer look into the spanish market design, Renewable Energy 89 (2016) 305-316. 
[69] REE, Statistical data.The Spanish Electricity System. Full report (2016), https://goo.gl/Vhk7oZ, [accessed 12/01/2019].

[70] Office of Gas and Electricity Markets, National Electricity Transmission System Security and Quality of Supply Standard (February 2017).

[71] REE, P.O. 3.7 - Aplicación de limitaciones a las entregas de producción de energía en situaciones no resolubles con la aplicación de los servicios de ajuste del sistema (2015), https://goo.gl/8USUHJ, [accessed 10/02/2019].

[72] S. Martin-Martinez, E. Gomez-Lazaro, A. Molina-Garcia, A. HonrubiaEscribano, Impact of wind power curtailments on the spanish power system operation, in: PES General Meeting| Conference \& Exposition, IEEE, 2014, pp. 1-5.

[73] REE, Statistical data.The Spanish Electricity System. Preliminary report 2017, https://www.ree. es/en/datos/publications/annual-system-report/ spanish-electricity-system-preliminary-report-2017, [accessed $12 / 01 / 2019]$.

[74] K. L. Hawker G.S, K. Bell12th International Workshop on Large-scale Integration of Wind Power into Power Systems as well as on Transmission Networks for Offshore Wind Power Plants ; Conference date: 22-10-2012 Through 24-10-2013.

[75] National Grid, Data Explorer Online - Balancing Data, https://www. nationalgrideso.com/balancing-data, [accessed 02/02/2019].

[76] Office of Gas and Electricity Markets, Transmission constraint licence condition guidance (2017).

[77] Dieter Helm, Cost of energy review, http://www.dieterhelm.co. uk/energy/energy/cost-of-energy-review-independent-report// [accessed 15/01/2019] (2017). 
[78] REE, P.O. 7.2 - Regulación secundaria (2015), https://goo.gl/r5M1Sr, [accessed 15/12/2018].

[79] ENTSO-E, Trans European Replacement Reserves Exchange (TERRE) Information, https://www.entsoe.eu/network_codes/eb/terre/, [accessed 30/02/2019].

[80] P. Frade, J. Santana, M. Shafie-khah, J. Catalão, Impact of tertiary reserve sharing in portugal, Utilities Policy 55 (2018) 167-177.

[81] Elexon, Final Modification Report P344 Project TERRE implementation into GB market arrangements (June 2018).

[82] ENTSO-E, Explanatory Document to All TSOs' proposal for the implementation framework for a European platform for the exchange of balancing energy from frequency restoration reserves with automatic activation in accordance with Article 21 of Commission Regulation (EU) 2017/2195 of 23 November 2017 establishing a guideline on electricity balancing (16 July 2018).

[83] R. F. Y. Liu, V. Terzija, Power system restoration: a literature review from 2006 to 2016, Journal of Modern Power Systems and Clean Energy 4 (3) (2016) 332-341.

[84] D. K. Maina, N. K. C. Nair, Recent advancements on power system restoration, IEEE Innovative Smart Grid Technologies - Asia (ISGT-Asia) (2017) $1-5$.

[85] J. Thomson, I. Talbot., Black start capability in the wind turbine market (10 jan 2018), https://goo.gl/E9TNjv, [accessed 26/01/2019].

[86] T. Soares, P. Pinson, T. V. Jensen, H. Morais, Optimal offering strategies for wind power in energy and primary reserve markets, IEEE Transactions on Sustainable Energy 7 (3) (2016) 1036-1045. 
[87] S. Camal, A. Michiorri, G. Kariniotakis, Optimal offer of automatic frequency restoration reserve from a combined PV/wind virtual power plant, IEEE Transactions on Power Systems 33 (6) (2018) 6155-6170. 